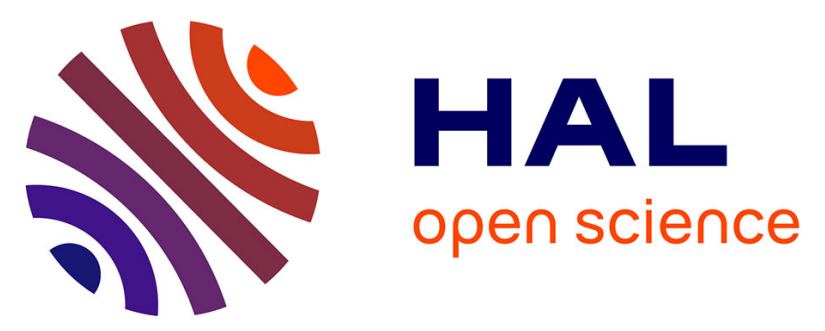

\title{
Atomic force microscopy nanoscale analysis: Impact of storage conditions on surface properties of whey protein powders
}

Claire Gaiani, Rana Omar, Sofiane El-Kirat-Chatel, Loubiana Cvetkovska, Marcela Alexander, Colin Ray, Jennifer Burgain, Gregory Francius

\section{To cite this version:}

Claire Gaiani, Rana Omar, Sofiane El-Kirat-Chatel, Loubiana Cvetkovska, Marcela Alexander, et al.. Atomic force microscopy nanoscale analysis: Impact of storage conditions on surface properties of whey protein powders. Food Hydrocolloids, 2021, 118, pp.106801. 10.1016/j.foodhyd.2021.106801 . hal-03200435

\section{HAL Id: hal-03200435 \\ https://hal.univ-lorraine.fr/hal-03200435}

Submitted on 26 Oct 2021

HAL is a multi-disciplinary open access archive for the deposit and dissemination of scientific research documents, whether they are published or not. The documents may come from teaching and research institutions in France or abroad, or from public or private research centers.
L'archive ouverte pluridisciplinaire HAL, est destinée au dépôt et à la diffusion de documents scientifiques de niveau recherche, publiés ou non, émanant des établissements d'enseignement et de recherche français ou étrangers, des laboratoires publics ou privés. 


\section{Atomic Force Microscopy Nanoscale Analysis: Impact of Storage Conditions on Surface Properties of Whey Protein Powders}

Claire Gaiani ${ }^{1,2 *}$, Rana Omar ${ }^{1,3}$, Sofiane El-Kirat-Chatel ${ }^{3}$, Loubiana Cvetkovska ${ }^{1}$, Marcela Alexander ${ }^{4}$, Colin Ray ${ }^{4}$, Jennifer Burgain ${ }^{1}$, Grégory Francius ${ }^{3 *}$

${ }^{1}$ Université de Lorraine, LIBio, F-54000 Nancy, France.

${ }^{2}$ Institut Universitaire de France (IUF), France.

${ }^{3}$ Université de Lorraine, CNRS, LCPME, UMR 7564, Villers-lès-Nancy, F-54600, France.

${ }^{4}$ Arla Foods Ingredients Group P/S, Sønderupvej 26, Videbæk DK-6920, Denmark.

\section{* Corresponding authors:}

gregory.francius@univ-lorraine.fr

claire.gaiani@univ-lorraine.fr

Phone: +33 372747416 


\section{Abstract}

Dairy powders are usually subjected to environmental variations during storage and/or shipment that strongly impact their chemical, nutritional and structural features. Nevertheless, these modifications are rarely investigated at the particle surface level, which represents the interface in contact with air, water, materials or other powders and directly influences powder functionalities. In this paper, atomic force microscopy (AFM) is used in imaging, nanoindentation and force spectroscopy modes to investigate the evolution of the surface properties such as the hydrophobicity and stiffness of whey protein powders at the nanoscale after controlled storage conditions. Our results evidenced that surface modifications are more enhanced by high storage temperature than storage time (for the same storage energy) and correspond to an increase of both surface hydrophobicity and heterogeneity. The strong impact of residual lactose in the powder (around $1.5 \%$ lactose) is also highlighted on these phenomena by performing surface comparisons with a reference powder ( $\beta$-lactoglobulin) without lactose. This reference powder permitted the discrimination between surface protein denaturation and surface lactosylation.
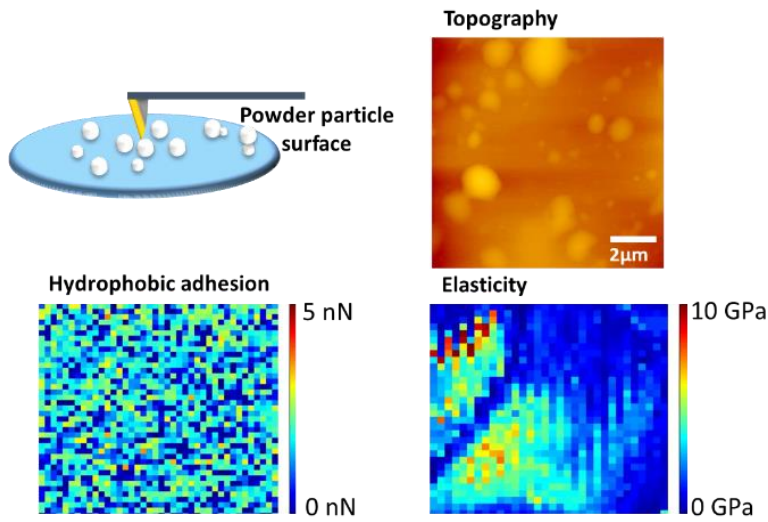

Key words: atomic force microscopy, nanoindentation, adhesion, storage, whey protein particles, $\beta$-lactoglobulin 


\section{Introduction}

Today, spray-drying is the main technique used for powder production to ensure milk preservation. Indeed, water removal from milk limits undesirable reactions (e.g. lipid oxidation, enzymatic reactions or bacterial growth) but also facilitates its transport by reducing the volumes. Spray-drying involves atomizing the liquid feed into a spray of droplets which are put into contact with hot air in a drying chamber (Schuck, 2002). Even if spray-drying is expected to keep as constant as possible the chemical, nutritional and microbiological properties of milk, it induces a segregation of milk components in the particle (i.e. between the core and the surface of the particle). For example, previous works revealed that surface composition of milk powder obtained by spray-drying is expressively different from its bulk composition (Burgain, et al., 2017; Kim, et al., 2009; Nikolova, et al., 2015). Therefore, proteins and fat are often overrepresented at the surface whereas minerals and lactose are over-represented in the core. This segregation may be accentuated with the spray-drying conditions or the properties of the concentrate : outlet/inlet temperature, viscosity and composition of the concentrate, or also the size of fat globules (Kim, et al., 2003). The distribution of the components within the particle is known to have many impacts on functional properties of the powder. Hence, when the surface of the food powder interacts with the surrounding environment, it subsequently affects its functionality. Various functional properties related to powder contact with water (Gaiani, et al., 2006) (wettability, dispersibility, solubility, hydration, ...), with air (oxidation, ...) (Vignolles, et al., 2007) or with other powders (flowability, caking...), (Petit, et al., 2017) may be affected by the process of spray-drying. As an example, the presence of fat at the powder surface makes the surface more hydrophobic and reduces its ability to reconstitute. The fat at the surface may also deteriorate powder nutritional properties as it will be more prone to oxidation. In contrast, the presence of hydrophilic groups (lactose or minerals) are known to improve the powder reconstitution by reducing the wetting time. Additionally, even if powder surface composition 
is well mastered after spray-drying the way the powders are stored or transported may strongly impact powder properties leading to poor reconstitution ability.

Various methodologies have been developed to characterize food powder surfaces in order to better understand their functional characteristics, (Burgain, et al., 2017) particularly scanning electron microscopy (SEM) and X-ray photoelectron spectroscopy (XPS) (Rouxhet, et al., 2011; Rouxhet, et al., 2008). SEM technique permits imaging of powder surfaces through the interaction of an electron beam with the sample. For food powders, samples should be coated by a conductive material before imaging which prevents further experiments on the powder and modifies the surface. SEM as well as XPS also require vacuum conditions, so it is not possible to observe how a powder can change with varying the environmental conditions (relative humidity and / or temperature). Therefore, degassing of powders presenting elevated water content may be impossible to perform. To overcome the mentioned drawbacks, atomic force microscopy (AFM) can be used instead (Burgain, et al., 2017). AFM is poorly used in the food powder field in comparison to e.g. materials or biological samples, despite this technique exhibiting promise for characterization of food surfaces and more particularly food powders surfaces at the nanoscale (Burgain, et al., 2017; Cárdenas-Pérez, et al., 2019; Yang, et al., 2007). AFM is a relevant tool in surface properties investigation for materials with different size and geometry under controlled conditions. It also allows simultaneous quantification of nanoscale changes in morphology and surface properties (e.g. elasticity and hydrophobicity), which can be related in some cases to surface composition modifications. Unlike the XPS and SEM, this technique does not require any special or invasive sample preparation, so it can be easily used to examine the influence of different environmental conditions (humidity and / or temperature) on the surface properties. For example, AFM investigations evidenced an increase in surface roughness of casein powder particles during its storage while SEM observations were unable to highlight this evolution (Burgain, Scher, et al., 2016). SEM and AFM imaging are 
complementary to investigate surface structure of skim and/or whole milk powders (MurrietaPazos, et al., 2011). The changes in surface properties of samples can be examined through force measurements using AFM functionalized or not according to the interaction to be studied. Furthermore, AFM allows mechanical investigation through nanoindentation method for a wide range of materials including food powders from the nano to the microscale (Burgain, et al., 2017; Marchetti, et al., 2016; Masterson, et al., 2008; Roa, et al., 2019). Besides, spatially resolved nanoindentation measurements allow stiffness mapping and thus locating soft and hard areas across the sample surface. For example, several studies demonstrated that such mechanical heterogeneities in sample surface could result from the presence of areas with different chemical composition or structural features (Liu, et al., 2011; Magonov, et al., 1997; Sabet, et al., 2018). Some authors also evidenced formation of hard/soft regions on the surface of milk powders subjected to long-term storage conditions using this technique (Burgain, Scher, et al., 2016; Prime, et al., 2011).

The objective of the present study was to investigate the surface modifications at the nanoscale occurring during storage of whey protein powders. For this purpose, two industrial whey protein powders: i) K03 a powder containing milk soluble proteins ( $\beta$-lactoglobulin and $\alpha$-lactalbumin) with fat and lactose traces; and ii) $\beta$-lactoglobulin $(\beta-\lg )$ a powder containing only proteins and used as reference, were investigated. In this study, the impact of storage conditions (temperature, duration and energy expressed in ${ }^{\circ} \mathrm{C}$.days) were investigated at the powder surface level with the determination of surface adhesion forces, rugosity and surface elasticity.

\section{Materials and Methods}

\subsection{Powder production and storage conditions}


Two freshly produced whey powders (namely $\beta$-lg and K03) were delivered by Arla Foods Ingredients (AFI, Denmark). K03 is a whey protein concentrate powder containing around 84 $\%$ of proteins ( $\beta$-lactoglobulin/ $/$ lactalbumin ratio $-75 / 25), 5 \%$ of lipids, $1.5 \%$ of lactose, $3 \%$ of ashes and $5 \%$ of water. The $\mathrm{a}_{\mathrm{w}}$ was under 0.2 when stored. $\beta$-lg powder is used as a reference powder for comparison purposes and contains $84 \%$ of proteins (only $\beta$-lactoglobulin) with lipids and lactose undetectable traces. These powders were stored under various storage conditions (Figure 1) directly after production. Four storage temperatures (i.e. 60, 55.5, 41 or $36{ }^{\circ} \mathrm{C}$ ), two energies of storage represented by the area under the curve (AUC $=428$ and 532 ${ }^{\circ}$ C.days) and two durations of storage (i.e. short times at 14 or 17 days and long times at 25 or 30 days) are combined to obtain six sets conditions. The two powders were stored in a controlled chamber with a sensor that records the temperature and relative humidity; the latter being set at $70 \%$ for all sets. As shown in Figure 1, high temperatures and short residence time were applied for sets 1,2 and 3 and long residence times and lower temperatures were applied for sets 4, 5 and 6. The AUC was lower for sets 1, 2, 4 and 5 (428 ${ }^{\circ}$ C.days) and higher for sets 3 and $6\left(532{ }^{\circ}\right.$ C.days $)$.

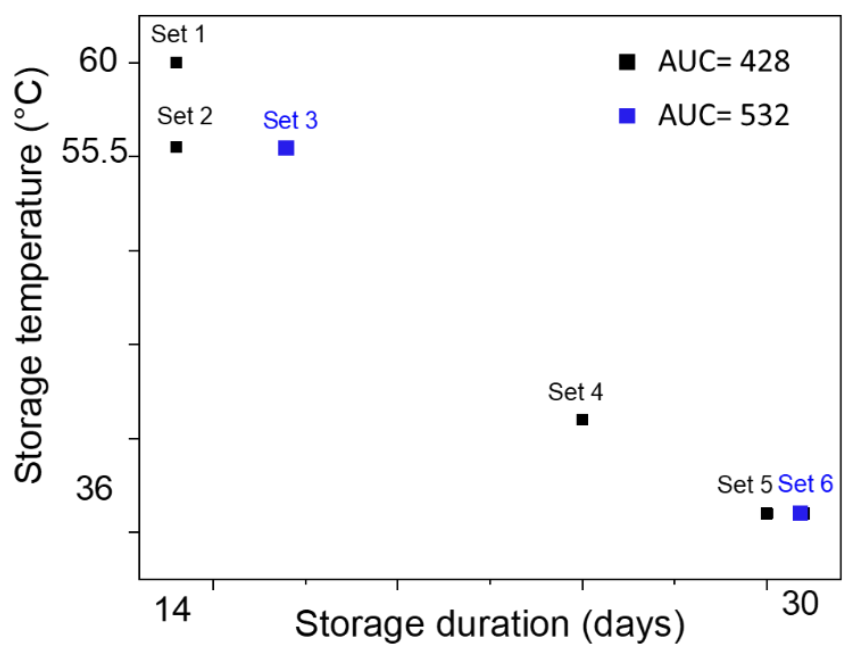

Figure 1. Storage pathways for the six storage sets. 


\subsection{Particle morphology observed by SEM}

The structural morphology was observed using a JEOL-NeoScope JCM-600 Scanning Electron Microscopy. Powders were placed on doubled side adhesive carbon tape on SEM holder and metalized (20 s at $20 \mathrm{~mA}$ ) with gold deposition (around $5 \mathrm{~nm}$ layer). Imaging was performed at an electron acceleration of $15 \mathrm{KV}$ using a secondary electron detector. SEM images were taken at $400 \mathrm{X}$ magnification.

\subsection{Particle surface properties probed by AFM}

\section{Sample preparation}

Prior to AFM experiments, WPI particles were sampled according to the following procedure. Using a plastic cone, a drop of araldite crystal glue was spread onto the surface of circular glass substrate in a homogenized way. After $\sim 15 \mathrm{~min}$, few $\mathrm{mg}$ of powder were deposited onto the substrate and excess of powder was removed with a nitrogen flow. Samples were ready after 2 hours when the glue was totally dried.

\section{Surface topography}

The surface topography of whey powder particles was probed with a MFP3D-BIO instrument (Asylum Research Technology, Oxford Instrument, Manheim, Germany) using gold coated AFM-tips (NPG, Bruker SAS, Palaiseau France) with a nominal spring constant of $\sim 0.12 \mathrm{~N} / \mathrm{m}$. Ethanol solvent was used instead of water to avoid powder reconstitution. At least 5 images of $10 \mu \mathrm{m} \times 10 \mu \mathrm{m}$ were obtained in contact mode at $1 \mathrm{~Hz}$ scan rate and with a maximal applied force of $500 \mathrm{pN}$ for each sample condition.

\section{Nanomechanics}

Mechanical properties of individual particles were probed at the nanoscale by AFM nanoindentation technique. The force-distance curves recorded by AFM were analyzed according to the theoretical Sneddon model to extract the mechanical properties (e.g. elasticity) 
(Burgain, et al., 2017; Burgain, Scher, et al., 2016; Prime, et al., 2011). Using a MFP3D-BIO instrument (Asylum Research Technology, Oxford Instrument, Manheim, Germany), defined areas were probed to generate elasticity maps. Measurements were performed in air and at room temperature with stiff cantilevers (RTESPA with $\sim 200 \mathrm{~N} / \mathrm{m}$ spring constant). The cantilever was calibrated onto sapphire wafers. At least 12 particles were analyzed per sample by recording elasticity maps of 256 or 1024 force curves on areas of $10 \mu \mathrm{m} \times 10 \mu \mathrm{m}$. All maps were processed under Matlab ${ }^{\mathrm{TM}}$ using an automated algorithm previously described.(Polyakov, et al., 2011)

\section{Adhesion forces}

The effect of storage on particles surface hydrophobicity was probed by AFM-based chemical force microscopy (CFM) and using a BioScope Resolve AFM (Bruker). Hydrophobicity measurements were performed in ethanol to avoid powder reconstitution and using gold-coated AFM tips (NPG-10, Bruker AXS, Palaiseau, France, spring constant $\sim 0.12 \mathrm{~N} / \mathrm{m}$ ) previously functionalized with alkanethiols by passive immersion in a solution of $1 \mathrm{mM}$ dodecanethiol during $14 \mathrm{~h}$ in the dark. Before each experiment, functionalized AFM-tips efficiency was systematically tested and calibrated onto hydrophobic coated gold substrates prepared at the same time (Alsteens, et al., 2007). Adhesion maps were obtained from the automated analysis of force distance curves recorded for each sample. Each map corresponds to the analysis of 1024 force distance curves on areas of $10 \mu \mathrm{m} \times 10 \mu \mathrm{m}$. Data were analyzed using Nanoscope Analysis 1.8 software and Matlab ${ }^{\mathrm{TM}}$.

\subsection{Particles surface elemental analysis by XPS}

XPS analyses were performed with a Kratos Axis Ultra (Kratos Analytical, Manchester, UK) spectrometer using a monochromatic $\mathrm{Al} \mathrm{K} \alpha$ source. The delay-line detector allows a high-count rate and the power applied to the X-ray anode was reduced to $90 \mathrm{~W}$ in order to avoid the X-ray 
induced degradation of the sample. The instrument work function was calibrated to give a binding energy $(\mathrm{BE})$ of $83.96 \mathrm{eV}$ for the $\mathrm{Au} 4 \mathrm{f}_{7 / 2}$ line for metallic gold and the spectrometer dispersion was adjusted to give a binding energy of $932.62 \mathrm{eV}$ for $\mathrm{Cu} 2 \mathrm{p}_{3 / 2}$ line for metallic copper. The powder samples were attached to the sample holder using a double side conductive tape and then evacuated overnight prior analyses. All spectra were recorded at $90^{\circ}$ take-off angle, the analyzed area being currently about $700 \mu \mathrm{m} \times 300 \mu \mathrm{m}$ (allowing the screening of hundreds of particles). XPS spectra were acquired and processed according to protocols previously described and were performed in duplicates for each samples (Gaiani, et al., 2006).

\subsection{Browning Index}

For each sample, $10 \mathrm{~g}$ of powder was poured in a Petri dish and color measurement was performed according to the three-color coordinates $\left(L^{*}, a^{*}, b^{*}\right)$ with a CR-400 chromameter (Konica Minolta). The $L^{*}$ value represents sample luminosity, varying from black (0) to white (100), the $a^{*}$ value represents the color varying from red (+) to green (-) and the $b^{*}$ value represents the color varying from yellow (+) to blue (-). Browning index (BI), defined as brown color purity, is one of the most common indicators of browning in food products (Maskan, 2001) and presented in eq (1) :

$$
B I=100 \times \frac{(x-0.31)}{0.17}
$$

where $x=\frac{\left(a^{*}+1.75 L^{*}\right)}{\left(5.645 L^{*}+a^{*}-3.012 b^{*}\right)}$

Each measured value was the mean of 3 independent determinations per powder and per set.

\subsection{Statistical analysis for AFM data interpretation}

Distribution of AFM data for both surface hydrophobicity and stiffness are often wide and asymmetric and/or follow a Poisson law as reported in Figures S3 and S8. Such wide 
distribution is related to samples surface heterogeneities as reported in several papers (Jin, et al., 2016; Mi, et al., 2008). In this case, comparison between samples surface properties become difficult particular when date distributions are overlapping due to large standard deviations. To overcome this, variance analysis (ANOVA) can be used to compare and differentiate the groups of data. For the sake of simplicity, we reported only mean and standard errors values in the tables of the manuscript. Statistical analyses of the AFM data were performed with ANOVA test using Dunn's method according to the difference of ranks as reported in Supporting Information (see Tables $\mathbf{S 2}$ and $\mathbf{S 3}$ ).

\section{Results and discussion}

\section{Topography monitoring of WPI particles during storage}

SEM combined with AFM measurements were performed to monitor the evolution of WPI particles morphology during different storage conditions (Burgain, El Zein, et al., 2016; Jones, et al., 2013). SEM micrographs reported in Figure 2 and Figure S1 illustrate the surface features of particles before and after storage. Before storage, size distribution of the particles was not homogeneous and the average particle diameters were in the range of 6 up to $28 \mu \mathrm{m}$ for $\beta-\lg$ and K03 powders. After storage in conditions of set 1, no significant evolution appears in the morphology and sizes of particles of either powders. Similar conclusions were also obtained for the other storage conditions (i.e. sets 2, 3, 4, 5 and 6, Figure S1). Whereas it was reported that temperature and humidity changes are major factors inducing WPI particles morphological modifications such as caking, swelling or surface crystallization (Burgain, El Zein, et al., 2016; Burgain, Scher, et al., 2016; Tunick, et al., 2016); it was not the case with the storage conditions applied here to whey protein and $\beta-\lg$ powders. 

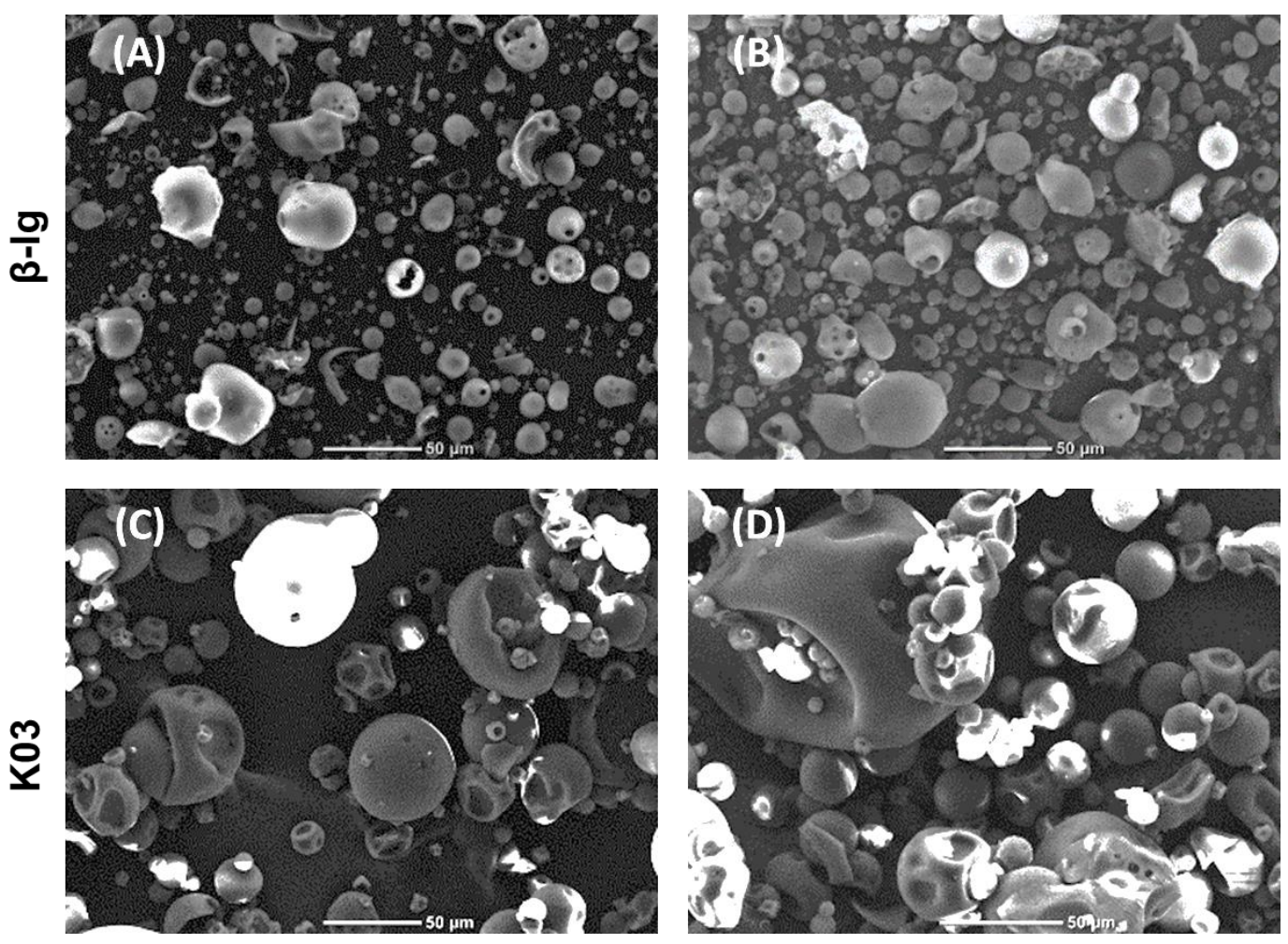

Figure 2. SEM images of whey protein powders before and after storage conditions of the set 1. (A) and (C) correspond to fresh $\beta-\lg$ and K03 samples respectively. (B) and (D) correspond to aged $\beta$-lg and K03 samples respectively.

Sample preparation for SEM analyses may impact the particle surface properties and morphology due to the needed coating with a thin gold layer (Burgain, Scher, et al., 2016). In this way, combination with AFM measurements are relevant to address both morphology and surface properties of the particles without any preparation impacting on the latter. The root mean square roughness (RMS) of the particles stored under high temperature conditions was in the range of $50-150 \mathrm{~nm}$ for both $\beta-\lg$ and K03 samples (Erreur! Source du renvoi introuvable.). We qualitatively noticed a slight decrease in particles RMS as illustrated in Figure S2A. Notice that the size of AFM sampling for each storage conditions is not enough to perform a quantitative analysis of particles RMS. Under low temperature storage (i.e. 41 or $36{ }^{\circ} \mathrm{C}$ ), a similar trend of the particles RMS was observed (Figure S2B). Despite the absence of significant morphological changes observed through SEM micrographs, the AFM analyses 
tend to suggest that slight nanoscale modifications may occur under both high and low temperature storage. Previous works reported that modifications in particles surface composition and component reorganization during storage may significantly impact their surface properties e.g. hydrophobicity and apparent stiffness (Burgain, El Zein, et al., 2016; Burgain, Scher, et al., 2016). To determine the evolution of those parameters during storage, AFM-based nanoindentation and CFM are more relevant and sensitive to give accurate and quantitative data on the different samples.

\section{Evolution of the powder surface hydrophobicity during storage}

CFM combined with XPS analyses were carried out to quantify the evolution of surface hydrophobicity of $\beta-\lg$ and K03 particles under high and low temperature storage as illustrated in Figures S3, S4, S5 and S6. Quantitative data concerning surface hydrophobicity were reported in Table 1 (for highest storage $\mathrm{T}^{\circ} \mathrm{C}$ ) and Table 2 (for lowest storage $\mathrm{T}^{\circ} \mathrm{C}$ ).

- Highest storage temperatures $\left(55.5-60.0^{\circ} \mathrm{C}\right)$

Before storage the hydrophobic features of $\beta-\lg$ are homogenously distributed over the particles surface in a narrow range from 0.2 to $1.0 \mathrm{nN}$ (Table 1 and Figures S3). Under high temperature storage, the surface hydrophobicity of $\beta-\lg$ particles is heterogeneously increased, on average, from about $0.40 \mathrm{nN}$ up to $1.29,1.38$ and $0.62 \mathrm{nN}$ for sets 1,2 and 3 respectively. Moreover, the hydrophobic features at particles surface are more heterogeneously distributed over a wider range from 0.2 to $3.5 \mathrm{nN}$ (see Figure S3A).

This heterogeneity progressively decreased from set 1 to set 3 conditions reflecting that i) high temperature increased hydrophobicity magnitude and heterogeneity while ii) long storage time tended towards attenuation of heterogeneity in values distribution. Similar behavior was also observed for K03 particles as illustrated in Figure S3, and Figure S5. So, surface 
hydrophobicity features of K03 particles were heterogeneously increased from about $0.38 \mathrm{nN}$ up to $2.62,1.40$ and $1.02 \mathrm{nN}$ for sets 1,2 and 3 respectively.

\begin{tabular}{cc|cc}
\hline $\begin{array}{c}\text { Physico-chemical properties of } \boldsymbol{\beta} \text {-lg } \\
\text { particles (2242 } \leq \boldsymbol{n} \leq \mathbf{6 1 2 1})\end{array}$ & \multicolumn{2}{c}{$\begin{array}{c}\text { Physico-chemical properties of K03 } \\
\text { particles }(\mathbf{2 2 9 3} \leq \boldsymbol{n} \leq \mathbf{5 5 9 1})\end{array}$} \\
\hline Hresh & $0.40 \pm 0.01$ & Fresh & $0.38 \pm 0.01$ \\
\hline Het 1 & $1.29 \pm 0.02$ & Set 1 & $2.62 \pm 0.04$ \\
Set 2 & $1.38 \pm 0.01$ & Set 2 & $1.40 \pm 0.01$ \\
Set 3 & $0.62 \pm 0.01$ & Set 3 & $1.06 \pm 0.02$ \\
\hline
\end{tabular}

Table 1. Evolution of surface hydrophobic forces $(\mathrm{nN})$ for $\beta-\lg$ (left) and K03 (right) powders under high temperature storage. Mean values and standard errors are reported herein with $n$ corresponding to the number of data per storage conditions. Statistical analysis by One Way ANOVA evidenced significant differences between all the sets and native properties, where $\mathrm{p}<0.001$ (see Table S2).

The formation of such hydrophobic domains or patches can be linked to the modification of the surface structure that may imply a chemical alteration. Therefore, these results suggest that particle surface property modifications may be related to molecular organization/migration and chemical reactions occurring at the surface of the powders that are stored at high storage temperatures (Burgain, El Zein, et al., 2016). Thus, storage induces heterogeneities at the particle surface for both the roughness and the surface hydrophobicity. Such observation has been already reported by Fyfe and coworkers. They evidenced a strong correlation between the surface hydrophobicity and the chemical composition at the particle surface (Fyfe, et al., 2011). Herein, element analysis by XPS were performed to support CFM analyses as shown in Table S1. 
XPS analysis of $\beta$-lg particles across the set of conditions considered at high temperatures revealed no or very weak variations in terms of $\mathrm{C}, \mathrm{O}$ and $\mathrm{N}$ surface amounts, with proportions of about 68, 17 and $15 \%$ as reported in Table S1. This is not the case for K03, where the deep analysis of its chemical environment indicated important modifications in $\mathrm{C}$ and $\mathrm{O}$ ones depending on the storage conditions. For K03 particles, the amount of $\mathrm{C}$ remained in the range about 71-72 \% regardless of storage conditions. Besides, the high temperature storage conditions resulted in significant variations in $\mathrm{O}$ and $\mathrm{N}$ surface amounts (from 17 to $10 \%$ and from 12 to $17 \%$ respectively). Indeed, a significant decrease in $\mathrm{O}$ amount was counterbalanced by an increase in $\mathrm{N}$ amount depending of the storage conditions.

From these results, and as shown in Figure 3, $\mathrm{C} / \mathrm{O}$ and $\mathrm{C}-\mathrm{C} /(\mathrm{C}-\mathrm{O}, \mathrm{C}=\mathrm{O}, \mathrm{O}-\mathrm{C}=\mathrm{O})$ ratios were calculated to estimate quantitatively the impact of high temperature storage on i) chemical composition and ii) hydrophobicity of the particles surface. Under high temperature storage, the $\mathrm{C} / \mathrm{O}$ ratio remained almost constant for $\beta$-lg particles with a value oscillating between 3.8 and 4.2 while it was significantly increased from $c a .4 .0$ up to $c a .6 .0-6.7$ for K03 particles across the same set of conditions. 

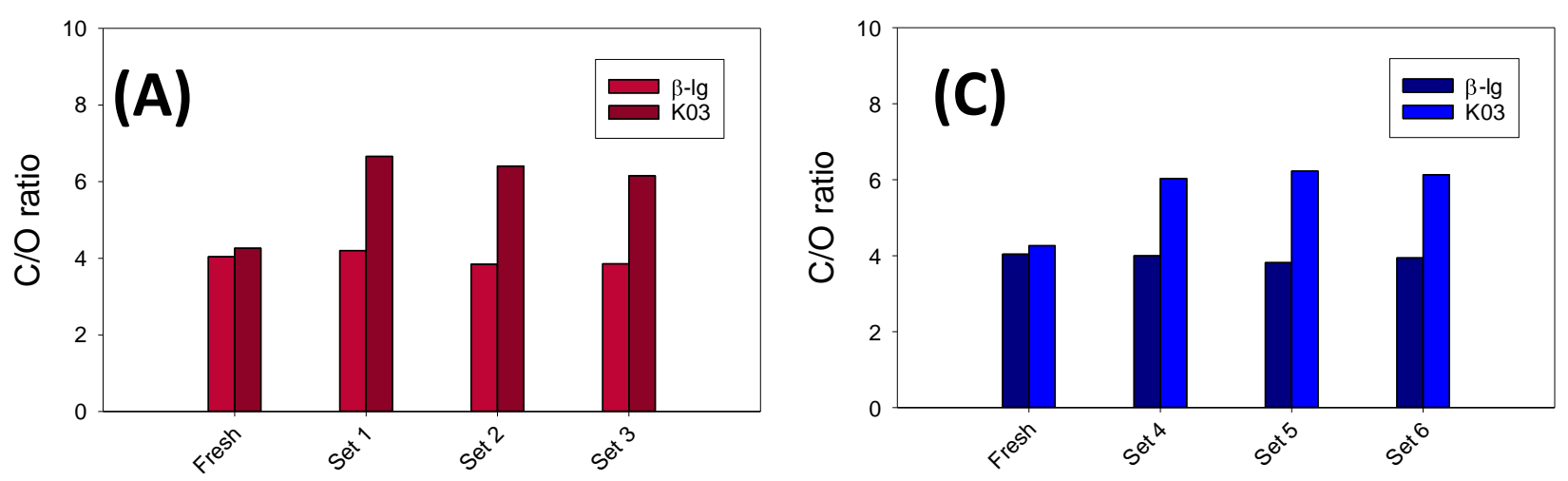

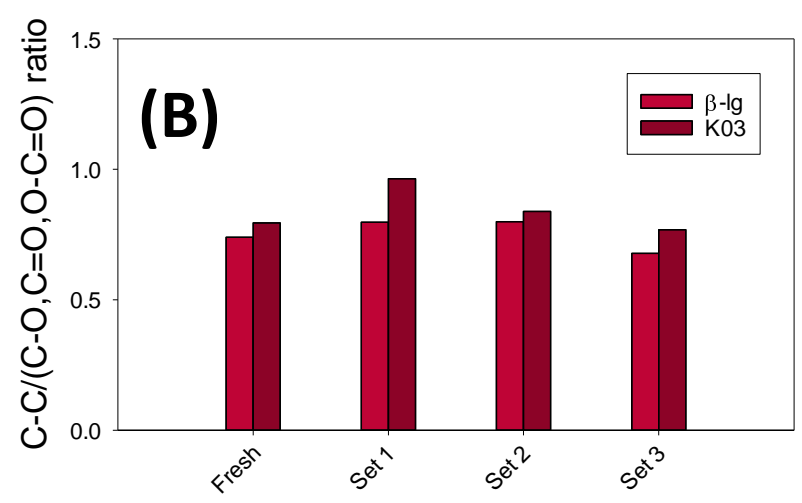

High temperature storage

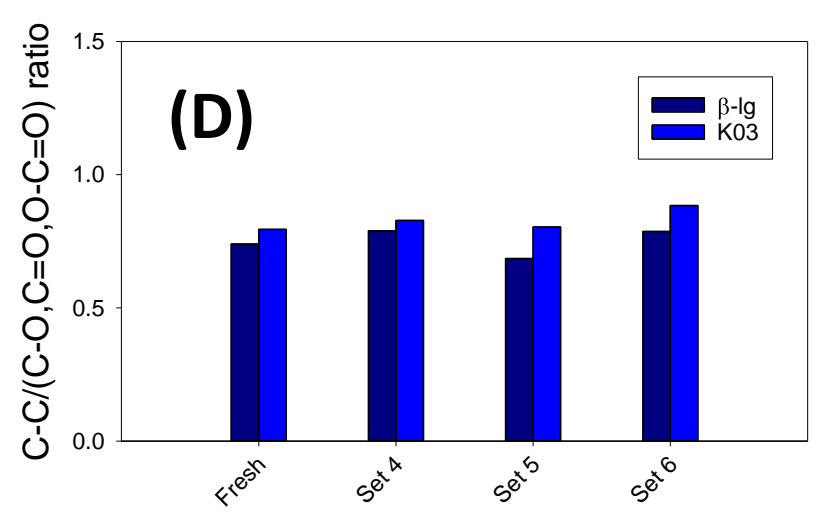

Low temperature storage

Figure 3. Evolution of the $\mathrm{C} / \mathrm{O}$ and $\mathrm{C}-\mathrm{C} /(\mathrm{C}-\mathrm{O}, \mathrm{C}=\mathrm{O}, \mathrm{O}-\mathrm{C}=\mathrm{O})$ ratios for $\beta-\lg (\mathrm{A}$ and $\mathrm{C})$ and $\mathrm{K} 03$

(B and D) particles stored under high and low temperature. Both ratios were calculated from XPS element analyses of the particles surface.

Such increase reflects an enhancement in surface hydrophobicity that is in accordance to CFM measurements. Concerning the $\mathrm{C}-\mathrm{C} /(\mathrm{C}-\mathrm{O}, \mathrm{C}=\mathrm{O}, \mathrm{O}-\mathrm{C}=\mathrm{O})$ ratio, similar behavior was observed with values remaining in the range of $0.7-0.8$ for $\beta$-lg whereas a slight increase from about 0.8 up to 1.0 was observed when $\mathrm{K} 03$ was stored under set 1 , set 2 and set 3 conditions. To sum-up, high temperature storage resulted in an increase of hydrophobicity magnitude and distribution heterogeneity at the particles surface whereas long storage time seemed to abate the surface heterogeneities (Jones, et al., 2013). This surface hydrophobicity increase is correlated with an increase of the $\mathrm{C} / \mathrm{O}$ ratio for $\mathrm{K} 03$ particles only (and not $\beta$-lac) meaning that the modifications at the surface are probably linked to the Maillard reaction (occurring in 
presence of lactose only and therefore only in K03) and not to proteins denaturation (occurring in $\mathrm{K} 03$ and $\beta$-lac).

\section{- Lowest storage temperatures $\left(36.0-41.0^{\circ} \mathrm{C}\right)$}

Under low temperature storage, the surface hydrophobicity of $\beta$-lg particles is heterogeneously increased from about $0.40 \mathrm{nN}$ up to 1.01 for set 4 and $0.73 \mathrm{nN}$ for set 6 while it appeared unchanged for set 5 (Figure S3, Table 2). Indeed, before storage the hydrophobic features of $\beta-\lg$ are homogenously distributed over the particles surface in a narrow range of 0 to $1 \mathrm{nN}$ (see Table 2 and Figure S6). Conversely to what was observed under high temperature storage, here surface heterogeneities and hydrophobicity dispersion values were less important and the values remained over the range from 0.2 to $1.0 \mathrm{nN}$ except for set 4 where hydrophobic features at particles surface are more heterogeneously distributed over a wider range from 0.1 to $2.5 \mathrm{nN}$. A very different behavior was also observed for K03 powder (Figure S3 and Table 2) with a surface hydrophobicity heterogeneously increasing from $0.38 \mathrm{nN}$ up to $1.62,1.55$ and $0.72 \mathrm{nN}$ for sets 4, 5 and 6 respectively. Besides, hydrophobic features of K03 are randomly distributed over the particles surface (see Figure S6) and in a narrow range from 0.1 to $0.5 \mathrm{nN}$ (Table 1 and Figure S3D). Conversely, when particles were stored under set 4, set 5 and set 6 conditions these hydrophobic features at the particles surface are more heterogeneously distributed over a wider range from 0.2 to $4.5 \mathrm{nN}$. Besides, the dispersion in values of surface hydrophobicity of the particles was dramatically decrease from set 4 to set 6 conditions reflecting that long storage time tended towards attenuation of heterogeneity in values distribution as it was also observed under higher temperature storage.

Physico-chemical properties of $\beta$-lg particles $(2242 \leq n \leq 6121)$
Physico-chemical properties of K03 particles $(2293 \leq n \leq 5591)$ 


\begin{tabular}{cc|cc}
\hline & Hydrophobicity $(\mathbf{n N})$ & & Hydrophobicity $(\mathbf{n N})$ \\
\hline Fresh & $0.40 \pm 0.01$ & Fresh & $0.38 \pm 0.01$ \\
\hline Set 4 & Set 4 & $1.62 \pm 0.03$ \\
Set 5 & $0.32 \pm 0.01 \pm 0.02$ & Set 5 & $1.55 \pm 0.04$ \\
Set 6 & $0.73 \pm 0.01$ & Set 6 & $0.72 \pm 0.01$ \\
\hline
\end{tabular}

$\overline{\text { Table 2. Evolution of surface hydrophobic forces }(\mathrm{nN}) \text { for } \beta \text {-lg (left) and K03 (right) powders }}$ under low temperature storage. Mean values and standard errors are reported herein with $n$ corresponding to the number of data per storage conditions. Statistical analysis by One Way ANOVA evidenced significant differences between all the sets and native properties, where $\mathrm{P}<0.001$ (see Table S2).

The evolution of spatial distribution of hydrophobic features over the particles surface during low temperature storage (i.e. $36-41^{\circ} \mathrm{C}$ ) was similar to observations performed under high temperature storage (see Figure S6). Indeed, the formation and evolution of hydrophobic domains are also linked to the modification in the surface structure and composition as supported by element analysis carried out by XPS (see Figure 3 and in Table S1). The elemental chemical environment indicated important modifications in $\mathrm{C}$ and $\mathrm{O}$ ones depending on the storage conditions in a similar way of what was reported under high temperature storage, where $\mathrm{C} / \mathrm{O}$ and $\mathrm{C}-\mathrm{C} /(\mathrm{C}-\mathrm{O}, \mathrm{C}=\mathrm{O}, \mathrm{O}-\mathrm{C}=\mathrm{O})$ ratios remained almost the same for $\beta-1 \mathrm{~g}$ particles with values oscillating between 3.8 and 4.2 while it was significantly increased from ca. 4.0 up to ca. 6.0 - 6.7 for $\mathrm{K} 03$ particles under the different set conditions. The $\mathrm{C}-\mathrm{C} /(\mathrm{C}-\mathrm{O}, \mathrm{C}=\mathrm{O}$, O$\mathrm{C}=\mathrm{O}$ ) ratio remained in the range of $0.7-0.8$ for $\beta-\lg$ whereas an increase from 0.8 up to 1.0 was observed when K03 was stored under sets 4, 5 and 6 conditions. To sum-up, the impact of low temperature storage on surface hydrophobicity of particles was similar to what was observed for high temperature storage. 
- Surface hydrophobicity related to the browning index

Under high temperature storage, the BI shown in Figure 4 was slightly increased from an initial value of 0.9 up to 4.3 for $\beta-\lg$ powder while it was strongly increased from 13.2 up to 41.8 for K03 powder. The BI reached to maximal values whatever the whey powder under set 1 storage condition. Under sets 2 and 3, the values of BI were very close but slightly lower than the one calculated under set 1 . Such results indicated that the higher is the temperature the more higher the $\mathrm{BI}$ and the therefore the Maillard reaction.

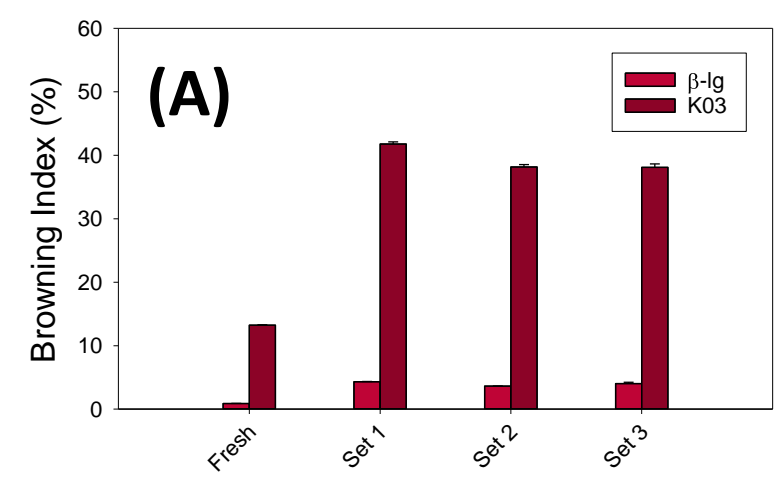

High temperature storage

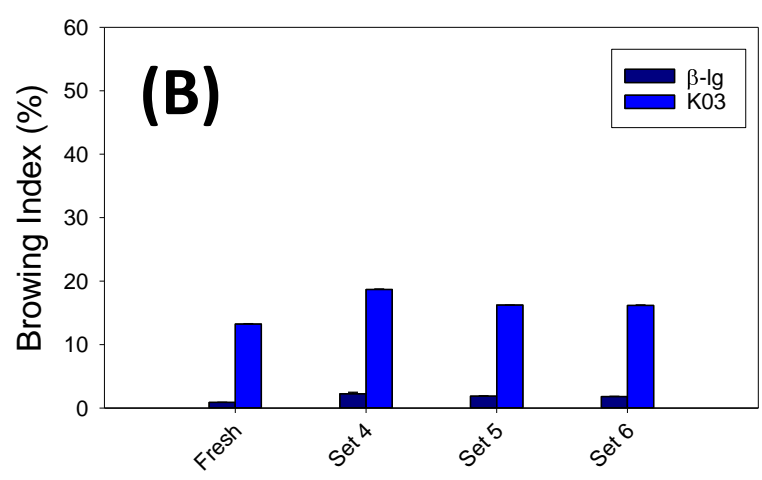

Low temperature storage

Figure 4. BI calculated for $\beta$-lg and K03 powders before and after aging under the different storage conditions $(\mathrm{A}-$ at the highest storage temperatures and $\mathrm{B}-$ at the lowest storage temperatures).

When the powders were subjected to low temperature storage, their corresponding BI were also increased but in lower proportions with maximal values of 2.3 and 18.7 under set 4 conditions for $\beta-\lg$ and $\mathrm{K} 03$, respectively. An increase in $\mathrm{BI}$ is generally related to an increase of brown color of milk powder and associated to the presence of Maillard pigments. A correlation between storage temperature and BI is clearly evidenced here. It means that the temperature triggers the Maillard reaction rate which is responsible to the production of brown pigments called melanoidins (Sunds, et al., 2018). The reference powder ( $\beta$-lg) shows a slight increase in the BI (values vary between 2 and 4). The storage duration does not tend to affect the BI 
significantly in comparison with small changes in the storage temperature $\left(60 \mathrm{vs} 55.5^{\circ} \mathrm{C}\right.$ and 41 vs $\left.36{ }^{\circ} \mathrm{C}\right)$. The increase in the hydrophobicity previously estimated from CFM and XPS analyses can be linked to the Maillard reaction as it leads to the production of a range of new molecules including hydrophobic ones (Burgain, El Zein, et al., 2016). Indeed, previous works evidenced that modifications of milk proteins surface hydrophobicity result from a balance between Maillard reaction and proteins conformation (Hiller, et al., 2010). Such complex combination is due to the fact that glycosylation decreases locally hydrophobicity while it can lead conformational changes (folding/unfolding, hydrophobic pocket formation) in proteins inducing an increase of surface hydrophobicity (Hiller, et al., 2010; Leonil, et al., 1997; Nacka, et al., 1998; Van Teeffelen, et al., 2005). Altogether surface analysis of the particles at the nanoscale are in good agreement with macroscopic investigation of the powders through its browning index (BI). Indeed, Figure $4 \mathrm{~A}$ reports the evolution of BI parameter under high temperature storage according to the different time conditions (sets 1,2 and 3). Our results are also in good agreement with previous works (Burgain, El Zein, et al., 2016; Norwood, et al., 2017).

\section{Impact of storage on nanomechanical properties of WPI particles}

Mechanical properties of $\beta$-lg and K03 particles were investigated in order to evidence a possible link with changes in surface hydrophobic features upon high and low temperature storages. Indeed, such modifications could result in whey proteins shell formation as previously evidenced in the case of casein powders (Burgain, Scher, et al., 2016) but never recorded for whey powders.

- Highest storage temperatures $\left(55.5-60.0^{\circ} \mathrm{C}\right)$

Evolution of both spatial and value distributions of elasticity for $\beta-\lg$ and K03 particles were illustrated by Figures S7, S8 and S9 according to high temperature storage conditions. Both 
fresh particles presented homogenous elasticity and K03 appeared stiffer with an elastic modulus of $4-7 \mathrm{GPa} v s 2-4 \mathrm{GPa}$ for $\beta$-lg particles. Also for both whey powders, the median elasticity of the particles remained roughly the same under set 1 and set 2 storage conditions while set 3 led to a very slight decreased in median elasticity for $\beta$-lg and a more pronounced one for K03 as reported in Table 3. As observed for surface hydrophobicity, high temperature storage resulted in stiffness heterogeneities and values dispersion whatever the set condition considered. These stiffness heterogeneities and the dispersion can be associated to the formation stiff patches or domains within a soft surrounding matrix. By contrast to $\beta$-lg particles, K03 powder exhibit critical stiff regions as red patches (see Figure S9). Indeed, under set 1 and set 2 conditions, there are no significant changes in statistical distribution of elasticity in K03 sample (except for set 3 presenting a lower elasticity) but the spatial distribution of the stiff domains seems totally different in terms of domain size and in-between distances. Here, K03 elasticity remained heterogeneous over a wide range of 2.0 up to $9.0 \mathrm{GPa}$ (except for set 3 exhibiting a narrow elasticity distribution). These stiff patches are randomly distributed over a surrounding matrix of about 0.5 up to $1.0 \mathrm{GPa}$ resulting in a broader elasticity distribution over a range of 0.5 up to $7.0 \mathrm{GPa}$. Surprisingly, a softening was observed for K03 according to only set 3 storage condition with a drop of a factor 2 whereas the stiffness remained almost unchanged for $\beta$-lg with values lower than $2 \mathrm{GPa}$ whatever the set considered.

\begin{tabular}{|c|c|c|c|}
\hline \multicolumn{2}{|c|}{$\begin{array}{l}\text { Nanomechanical properties of } \beta \text {-lg particles } \\
\qquad\left(2242 \leq n^{*} \leq 6121\right)\end{array}$} & \multicolumn{2}{|c|}{\begin{tabular}{|} 
Nanomechanical properties of K03 particles \\
$\qquad(2293 \leq n \leq 5591)$ \\
\end{tabular}} \\
\hline & Elasticity (GPa) & & Elasticity (GPa) \\
\hline Fresh & $2.15 \pm 0.01$ & Fresh & $5.52 \pm 0.04$ \\
\hline Set 1 & $2.71 \pm 0.04$ & Set 1 & $4.92 \pm 0.05$ \\
\hline Set 2 & $2.76 \pm 0.03$ & Set 2 & $5.23 \pm 0.04$ \\
\hline Set 3 & $2.01 \pm 0.04$ & Set 3 & $2.40 \pm 0.07$ \\
\hline
\end{tabular}


Table 3. Evolution of particles elasticity (GPa) for $\beta$-lg (left) and K03 (right) whey powders under high temperature storage. Mean values and standard errors are reported herein with $n$ corresponding to the number of data per storage conditions. Statistical analysis by One Way ANOVA evidenced significant differences between all the sets and native properties, where $\mathrm{P}<0.001$ (see Table S3).

The important mechanical changes in K03 particles might be related to the fact that the storage at high temperature stimulates the formation of aggregates and Maillard compounds leading to heterogeneity in particles stiffness.(Anema, et al., 2006; Burgain, et al., 2017) In particular, the elastic modulus describes the internal organization of various components forming the material. Thus, the protein aggregation is a result of non-covalent interactions (hydrophobic) between these components that harden the surface while the drying process results in changes upon moisture removal (Burgain, Scher, et al., 2016). This can support our data concerning the increase in the particles elasticity of K03 powder.(Zhou, et al., 2008)

\section{- Lowest storage temperatures $\left(36.0-41.0^{\circ} \mathrm{C}\right)$}

The impact of low temperature storage on $\beta-\lg$ and K03 particles stiffness is illustrated by Figures S7, S8, S10 and Table 4. For both powders a significant decrease in median elasticity was observed for the particles under set 4 , set 5 and set 6 storage conditions when compared to the fresh powders. Indeed, particles stiffness collapsed from 2.0 to $0.6 \mathrm{GPa}$ for $\beta-\lg$ and from 5.5 to $2.7 \mathrm{GPa}$ for K03 as reported in Table 4 and Table S3. However, while $\beta$-lg values decreased amongst the different sets, K0 values were constant between set 4, 5 and 6 . Such decrease in stiffness may result from a storage above the glass transition temperature. In this case, the fresh powder is stiffer as it is in the glassy state and stored samples are in the rubbery state. Above the glass transition temperature, a collapse of the structure can occur which can be evidenced by nanomechanical measurements (Burgain, et al., 2020; Palzer, 2007). In all cases, 
the elasticity was not homogenous and particles presented randomly distributed stiff patches reflecting the presence of enriched domains in some components and/or differently organized. The stiff patches could be related to lactose crystallization and early Maillard reactions.

However, the number of stiff patches seems to be lower under low temperature storage (Figure S10) than under high temperature storage (Figure S9) as well as the magnitude of stiffening. In this way, the formation and the number of stiff domains may depend on the storage temperature, in which the lower the storage temperature is, the lower the number of patches. Such trend is supported by comparison between spatial distribution of particles stiffness reported in Figure S9 and Figure S10. It can be also highlighted that high and low temperature storages resulted in a decrease of the stiffness of the surrounding matrix whatever the particle considered as illustrated by the elasticity spatial distributions reported for each particle in Figure S9 and Figure S10. Such stiffness decrease of the surrounding matrix appeared more pronounced for $\mathrm{K} 03$ than the one related to $\beta-\lg$. This discrepancy may be explained by that fact that $\mathrm{K} 03$ is composed of various proteins ( $\beta$-lactoglobulin, $\alpha$-lactalbumin, glycomacropeptides and many more) which should be modified and/or altered by temperature storage in a highly heterogeneous way leading to more disorganized structures in particles contrary to pure $\beta-\lg$.

\begin{tabular}{|c|c|c|c|}
\hline \multicolumn{2}{|c|}{$\begin{array}{l}\text { Nanomechanical properties of } \beta \text {-lg particles } \\
\qquad(2242 \leq n \leq 6121)\end{array}$} & \multicolumn{2}{|c|}{\begin{tabular}{|} 
Nanomechanical properties of K03 particles \\
$(2293 \leq n \leq 5591)$ \\
\end{tabular}} \\
\hline & Elasticity (GPa) & & lasticity (GPa) \\
\hline Fresh & $2.15 \pm 0.01$ & Fresh & $5.52 \pm 0.04$ \\
\hline Set 4 & $2.27 \pm 0.07$ & Set 4 & $2.95 \pm 0.05$ \\
\hline Set 5 & $0.96 \pm 0.02$ & Set 5 & $3.11 \pm 0.05$ \\
\hline Set 6 & $0.62 \pm 0.02$ & Set 6 & $2.70 \pm 0.06$ \\
\hline
\end{tabular}

Table 4. Evolution of particles elasticity (GPa) in $\beta$-lg (left) and K03 (right) whey powders under low temperature storage Mean values and standard errors are reported herein with $n$ 
corresponding to the number of data per storage conditions. Statistical analysis by One Way ANOVA evidenced significant differences between all the sets and native properties, where $\mathrm{P}<0.001$ (see Table S3).

It can be additionally noticed that the increase of storage time tends to ease the particles softening in both $\beta-\lg$ and K03 powders. Long storage duration should allow enough time for molecular reorganization due to water mobility above the glass transition temperature. It is well known that the elastic modulus increases in the protein layer with time. Despite the decrease in the elasticity in set 3 , we expected that powders with high protein concentration have higher elastic modulus which can be explained by thick and deep ridges and dents (Tunick, et al., 2016). In the present, the behavior of whey protein isolate (WPI) powders was opposite to the one previously described for casein powders (Burgain, Scher, et al., 2016). In casein powders, proteins were present in a micellar structure and even if Maillard reaction occurred in these products, it was not linked to nanomechanical surface properties evolution. On the contrary, whey proteins are present as individual monomers with a well-defined secondary structure which make them particularly susceptible to heat-induced changes.

\section{Conclusion}

Surface properties (hydrophobicity, elasticity, chemical composition) of whey powders are important parameters that influence products functionalities (wettability, dispersibility, solubility, hydration, flowability...). Here, we combined SEM, XPS, AFM-based imaging, CFM and nanoindentation to determine the effect of different storage conditions on the surface properties of high protein dairy powders at the nanoscale ( $\beta-\lg$ and K03). SEM and AFM imaging revealed that storage at high temperature do not influence the particle size but led to smoother surfaces. These morphological changes were correlated to a chemical reorganization 
of the surface which resulted in the formation of strongly hydrophobic patches as determined by XPS and CFM analysis, respectively. Nanoindentation revealed that storage at high temperature induce mechanical heterogeneities on particle surfaces with stiff domains surrounded by softer areas. These physico-chemical changes at the nanoscale were more pronounced for K03 than for $\beta$-lg and the corresponding analysis of the BI suggested that the increased surface hydrophobicity and mechanical changes could be attributed to protein denaturation and lactosylation together with compounds rearrangement and migration at the particle surface. Finally, these results highlight the strong effect of high temperature during powder storage and illustrate how nanoscale analysis can help to predict the functional properties and quality of whey powders.

\section{Acknowledgements}

The authors thank Aurélien Renard from the Spectroscopy and Microscopy Service Facility (SMI) of LCPME (Université de Lorraine-CNRS - http://www.lcpme.cnrs-nancy.fr) for XPS analyses. 


\section{References}

Alsteens, D., Dague, E., Rouxhet, P. G., Baulard, A. R., \& Dufrene, Y. F. (2007). Direct measurement of hydrophobic forces on cell surfaces using AFM. Langmuir, 23(24), 11977-11979.

Anema, S. G., Pinder, D. N., Hunter, R. J., \& Hemar, Y. (2006). Effects of storage temperature on the solubility of milk protein concentrate (MPC85). Food Hydrocolloids, 20(2-3), 386-393.

Burgain, J., Cvetkovska, L., Paris, C., Omar, R., Alexander, M., Nielsen, J. H., Ray, C., Francius, G., El-Kirat-Chatel, S., \& Gaiani, C. (2020). Maillard reaction-induced protein lactosylation is monitored by storage path. Submitted.

Burgain, J., El Zein, R., Scher, J., Petit, J., Norwood, E.-A., Francius, G., \& Gaiani, C. (2016). Local modifications of whey protein isolate powder surface during high temperature storage. Journal of Food Engineering, 178, 39-46.

Burgain, J., Petit, J., Scher, J., Rasch, R., Bhandari, B., \& Gaiani, C. (2017). Surface chemistry and microscopy of food powders. Progress in Surface Science, 92(4), 409-429.

Burgain, J., Scher, J., Petit, J., Francius, G., \& Gaiani, C. (2016). Links between particle surface hardening and rehydration impairment during micellar casein powder storage. Food Hydrocolloids, 61, 277-285.

Cárdenas-Pérez, S., Chanona-Pérez, J. J., Méndez-Méndez, J. V., Arzate-Vázquez, I., Hernández-Varela, J. D., \& Vera, N. G. (2019). Recent advances in atomic force microscopy for assessing the nanomechanical properties of food materials. Trends in Food Science \& Technology, 87, 59-72.

Fyfe, K. N., Kravchuk, O., Le, T., Deeth, H. C., Nguyen, A. V., \& Bhandari, B. (2011). Storage induced changes to high protein powders: influence on surface properties and solubility. Journal of the Science of Food and Agriculture, 91(14), 2566-2575.

Gaiani, C., Ehrhardt, J. J., Scher, J., Hardy, J., Desobry, S., \& Banon, S. (2006). Surface composition of dairy powders observed by X-ray photoelectron spectroscopy and effects on their rehydration properties. Colloids Surf B Biointerfaces, 49(1), 71-78.

Hiller, B., \& Lorenzen, P. C. (2010). Functional properties of milk proteins as affected by Maillard reaction induced oligomerisation. Food Research International, 43(4), 11551166.

Jin, X., \& Kasal, B. (2016). Adhesion force mapping on wood by atomic force microscopy: influence of surface roughness and tip geometry. Royal Society Open Science, 3(10), 160248.

Jones, J. R., Prime, D., Leaper, M. C., Richardson, D. J., Rielly, C. D., \& Stapley, A. G. F. (2013). Effect of processing variables and bulk composition on the surface composition of spray dried powders of a model food system. Journal of Food Engineering, 118(1), 19-30.

Kim, E. H. J., Chen, X. D., \& Pearce, D. (2009). Surface composition of industrial spray-dried milk powders. 2. Effects of spray drying conditions on the surface composition. Journal of Food Engineering, 94(2), 169-181. 
Kim, E. H. J., Dong Chen, X., \& Pearce, D. (2003). On the Mechanisms of Surface Formation and the Surface Compositions of Industrial Milk Powders. Drying Technology, 21(2), 265-278.

Leonil, J., Molle, D., Fauquant, J., Maubois, J. L., Pearce, R. J., \& Bouhallab, S. (1997). Characterization by Ionization Mass Spectrometry of Lactosyl $\beta$-Lactoglobulin Conjugates Formed During Heat Treatment of Milk and Whey and Identification of One Lactose-Binding Site1. Journal of Dairy Science, 80(10), 2270-2281.

Liu, Y. H., Wang, D., Nakajima, K., Zhang, W., Hirata, A., Nishi, T., Inoue, A., \& Chen, M. W. (2011). Characterization of nanoscale mechanical heterogeneity in a metallic glass by dynamic force microscopy. Physical Review Letters, 106(12), 125504.

Magonov, S. N., Elings, V., \& Whangbo, M. H. (1997). Phase imaging and stiffness in tappingmode atomic force microscopy. Surface Science, 375(2-3), L385-L391.

Marchetti, M., Wuite, G., \& Roos, W. H. (2016). Atomic force microscopy observation and characterization of single virions and virus-like particles by nano-indentation. Curr Opin Virol, 18, 82-88.

Maskan, M. (2001). Kinetics of colour change of kiwifruits during hot air and microwave drying. Journal of Food Engineering, 48(2), 169-175.

Masterson, V. M., \& Cao, X. (2008). Evaluating particle hardness of pharmaceutical solids using AFM nanoindentation. International Journal of Pharmaceutics, 362(1-2), 163171.

Mi, B., \& Elimelech, M. (2008). Chemical and physical aspects of organic fouling of forward osmosis membranes. Journal of Membrane Science, 320, 292-302.

Murrieta-Pazos, I., Gaiani, C., Galet, L., Cuq, B., Desobry, S., \& Scher, J. (2011). Comparative study of particle structure evolution during water sorption: skim and whole milk powders. Colloids Surf B Biointerfaces, 87(1), 1-10.

Nacka, F., Chobert, J. M., Burova, T., Leonil, J., \& Haertle, T. (1998). Induction of new physicochemical and functional properties by the glycosylation of whey proteins. Journal of Protein Chemistry, 17(5), 495-503.

Nikolova, Y., Petit, J., Sanders, C., Gianfrancesco, A., Scher, J., \& Gaiani, C. (2015). Toward a better determination of dairy powders surface composition through XPS matrices development. Colloids Surf B Biointerfaces, 125, 12-20.

Norwood, E.-A., Pezennec, S., Burgain, J., Briard-Bion, V., Schuck, P., Croguennec, T., Jeantet, R., \& Le Floch-Fouéré, C. (2017). Crucial role of remaining lactose in whey protein isolate powders during storage. Journal of Food Engineering, 195, 206-216.

Palzer, S. (2007). Chapter 13 Agglomeration of dehydrated consumer foods. In A. D. Salman, M. J. Hounslow, J. P. K. Seville, A. D. Salman, M. J. Hounslow \& J. P. K. Seville (Eds.), Handbook of Powder Technology (Vol. 11, pp. 591-671).

Petit, J., Michaux, F., Jacquot, C., Chávez Montes, E., Dupas, J., Girard, V., Gianfrancesco, A., Scher, J., \& Gaiani, C. (2017). Storage-induced caking of cocoa powder. Journal of Food Engineering, 199, 42-53.

Polyakov, P., Soussen, C., Duan, J., Duval, J. F. L., Brie, D., \& Francius, G. (2011). Automated force volume image processing for biological samples. PLoS One, 6(4), e18887. 
Prime, D. C., Stapley, A. G. F., Rielly, C. D., Jones, J. R., \& Leaper, M. C. (2011). Analysis of Powder Caking in Multicomponent Powders Using Atomic Force Microscopy to Examine Particle Properties. Chemical Engineering \& Technology, 34(1), 98-102.

Roa, S., Haberkorn, N., \& Sirena, M. (2019). Atomic force microscopy nano-indentation for testing mechanical properties in thin films. Materials Today: Proceedings, 14, 113-116.

Rouxhet, P. G., \& Genet, M. J. (2011). XPS analysis of bio-organic systems. Surface and Interface Analysis, 43(12), 1453-1470.

Rouxhet, P. G., Misselyn-Bauduin, A. M., Ahimou, F., Genet, M. J., Adriaensen, Y., Desille, T., Bodson, P., \& Deroanne, C. (2008). XPS analysis of food products: toward chemical functions and molecular compounds. Surface and Interface Analysis, 40(3-4), 718-724.

Sabet, F. A., Su, F. Y., McKittrick, J., \& Jasiuk, I. (2018). Mechanical Properties of Model Two-Phase Composites with Continuous Compared to Discontinuous Phases. Advanced Engineering Materials, 20(10).

Schuck, P. (2002). Spray drying of dairy products: state of the art. Lait, 82(4), 375-382.

Sunds, A. V., Rauh, V. M., Sørensen, J., \& Larsen, L. B. (2018). Maillard reaction progress in UHT milk during storage at different temperature levels and cycles. International Dairy Journal, 77, 56-64.

Tunick, M. H., Thomas-Gahring, A., Van Hekken, D. L., Iandola, S. K., Singh, M., Qi, P. X., Ukuku, D. O., Mukhopadhyay, S., Onwulata, C. I., \& Tomasula, P. M. (2016). Physical and chemical changes in whey protein concentrate stored at elevated temperature and humidity. Journal of Dairy Science, 99(3), 2372-2383.

Van Teeffelen, A. M. M., Broersen, K., \& de Jongh, H. H. J. (2005). Glucosylation of $\beta$ lactoglobulin lowers the heat capacity change of unfolding; a unique way to affect protein thermodynamics. Protein Science, 14(8), 2187-2194.

Vignolles, M.-L., Jeantet, R., Lopez, C., \& Schuck, P. (2007). Free fat, surface fat and dairy powders: interactions between process and product. A review. Le Lait, 87(3), 187-236.

Yang, H., Wang, Y., Lai, S., An, H., Li, Y., \& Chen, F. (2007). Application of atomic force microscopy as a nanotechnology tool in food science. Journal of Food Science, 72(4), R65-75.

Zhou, P., Liu, X., \& Labuza, T. P. (2008). Effects of moisture-induced whey protein aggregation on protein conformation, the state of water molecules, and the microstructure and texture of high-protein-containing matrix. Journal of Agricultural and Food Chemistry, 56(12), 4534-4540. 


\section{Supporting Information}

\section{Atomic Force Microscopy Nanoscale Analysis: Impact of Storage Conditions on Surface Properties of Whey Protein Powders}

Claire Gaiani ${ }^{1,2 *}$, Rana Omar ${ }^{1,3}$, Sofiane El-Kirat-Chatel ${ }^{3}$, Loubiana Cvetkovska ${ }^{1}$, Marcela Alexander ${ }^{4}$, Colin Ray ${ }^{4}$, Jennifer Burgain ${ }^{1}$, Grégory Francius ${ }^{3 *}$

${ }^{1}$ Université de Lorraine, LIBio, F-54000 Nancy, France.

${ }^{2}$ Institut Universitaire de France (IUF), France.

${ }^{3}$ Université de Lorraine, CNRS, LCPME, UMR 7564, Villers-lès-Nancy, F-54600, France.

${ }^{4}$ Arla Foods Ingredients Group P/S, Sønderupvej 26, Videbæk DK-6920, Denmark.

\footnotetext{
* Corresponding authors:

gregory.francius@univ-lorraine.fr

claire.gaiani@univ-lorraine.fr

Phone: +33372747416
} 

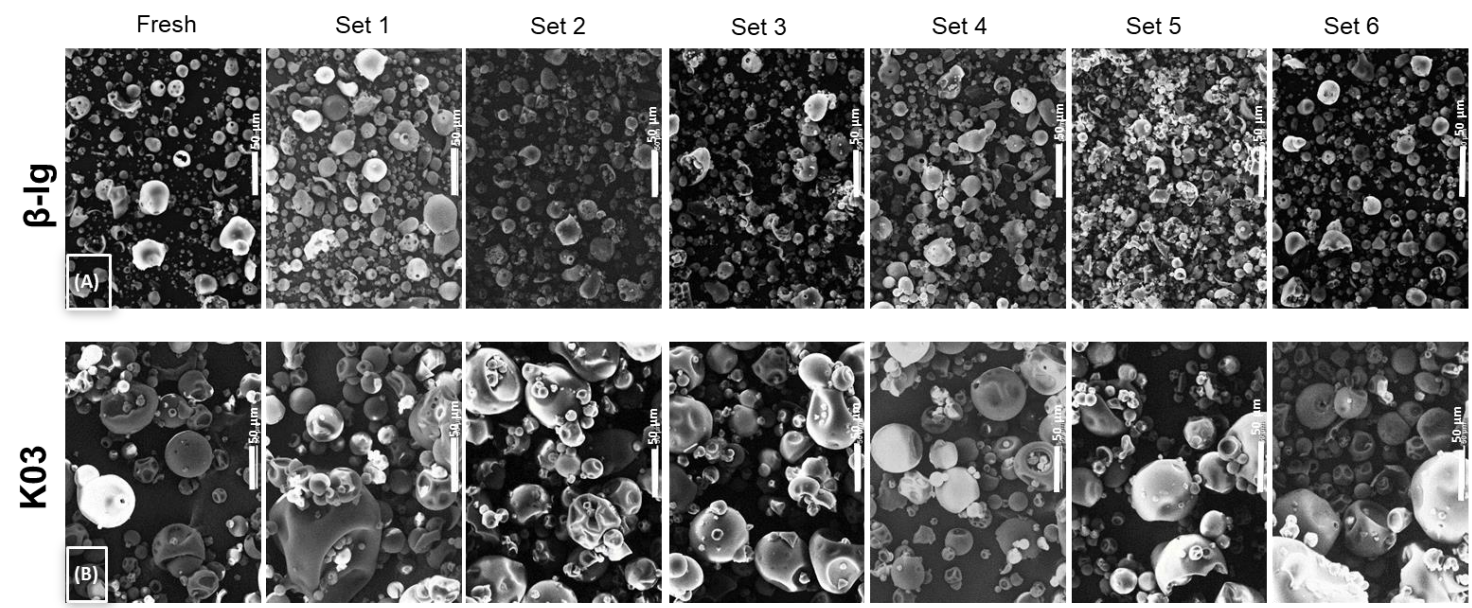

2 Figure S1. SEM images of the particle surface of $\beta$-lg (top) and K03 powders (bottom) during 3 storage. (A) and (B) refer to fresh $\beta-1 g$ and K03, respectively. Scale bar $50 \mu \mathrm{m}$ and 4 magnification 400X. 


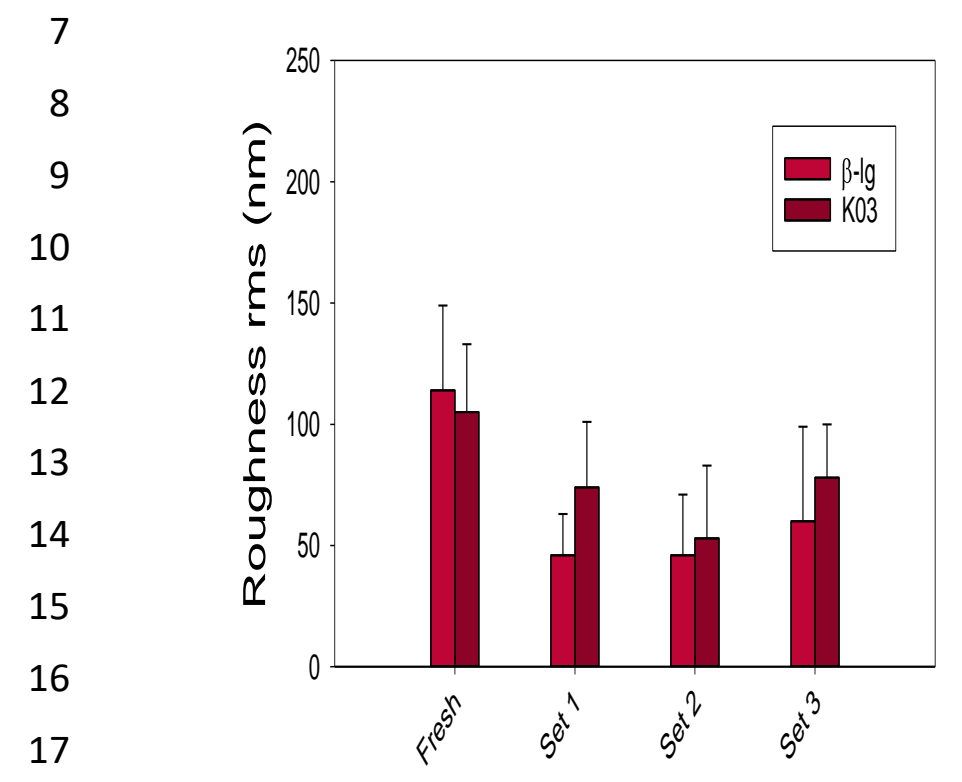

18

19

20

21

22

23

24

25

26

27

28

29

30

31

32

33

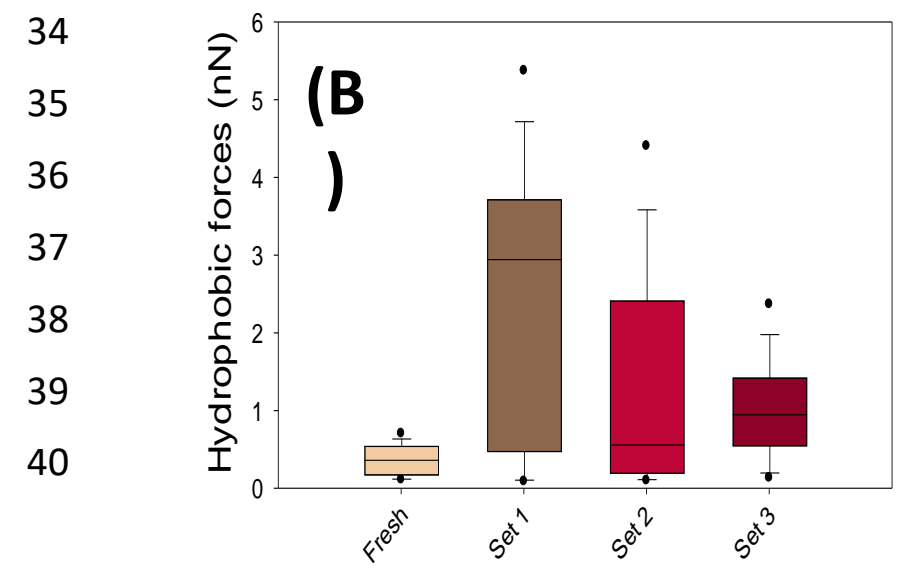

High temperature storage curvature.

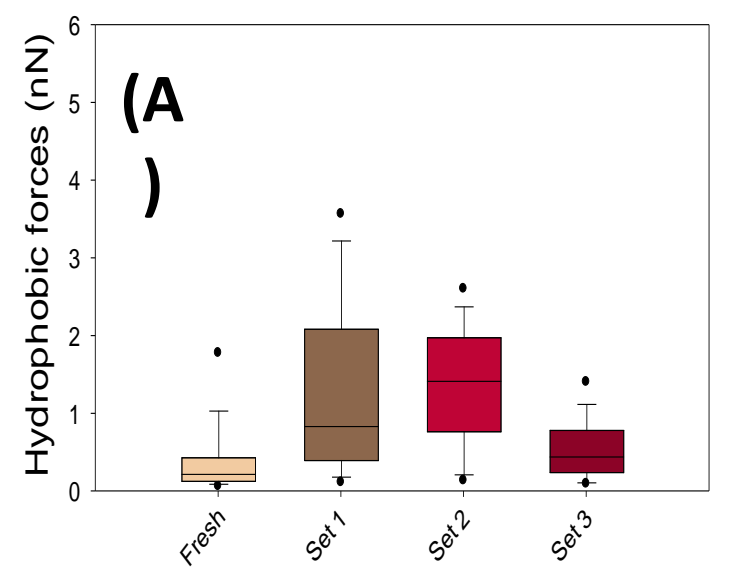

J

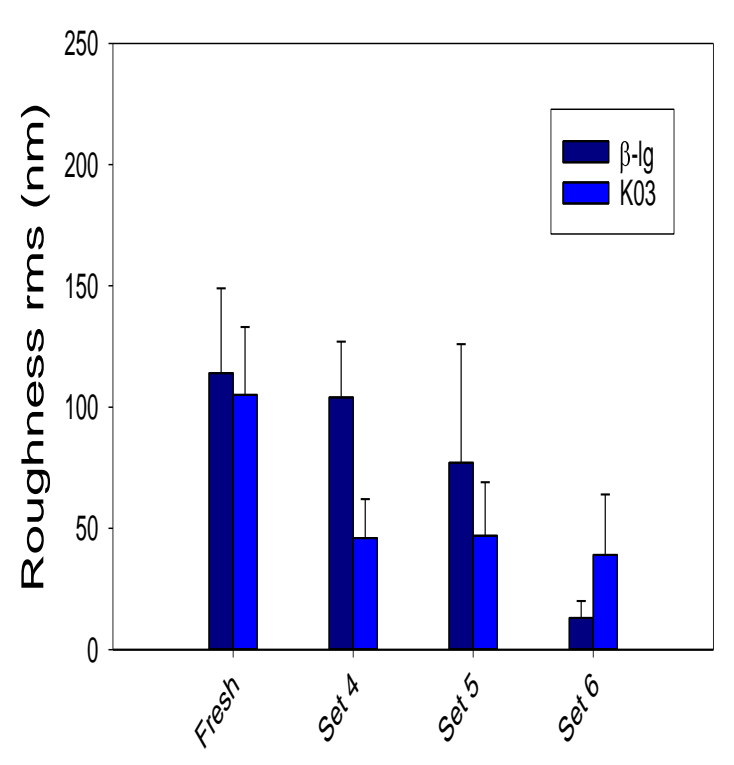

Low temperature storage

Figure S2. Evolution of milk powder particles roughness under (a) high temperature and (b) low temperature storages. Average values and standard deviations were obtained from analysis of at least 5 AFM images $(10 \times 10 \mu \mathrm{m})$ after second order flattening to remove particle
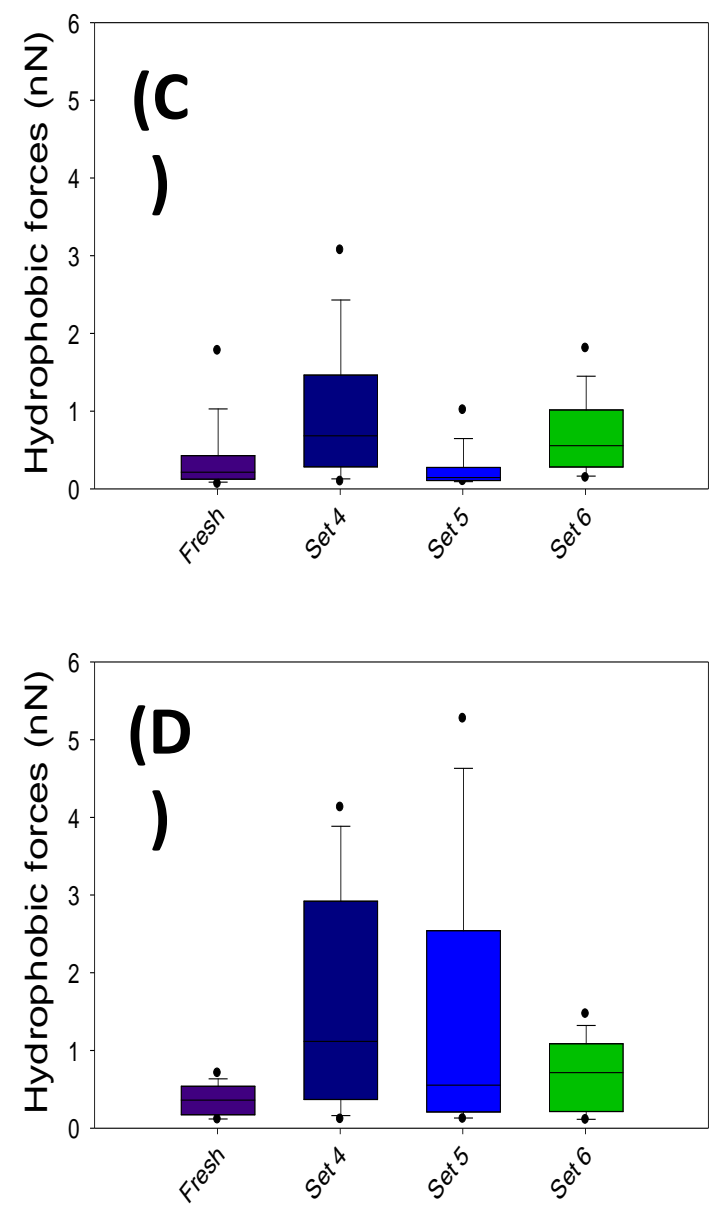

Low temperature storage 
56

57

58

59

60

61

62

63

64

65

66

67

68

69

70

71

Figure S3. Evolution of the surface hydrophobicity under high temperature storage for $\beta-\lg (\mathrm{A})$ and K03 (B) particles and under low temperature storage for $\beta-\lg (\mathrm{C})$ and K03 (D) particles. Kruskal-Wallis One Way Analysis of Variance on Ranks (ANOVA) analysis performed on the whole data sets indicated that there is a statistically significant differences $(\mathrm{P}=<0.001)$ between all set conditions.
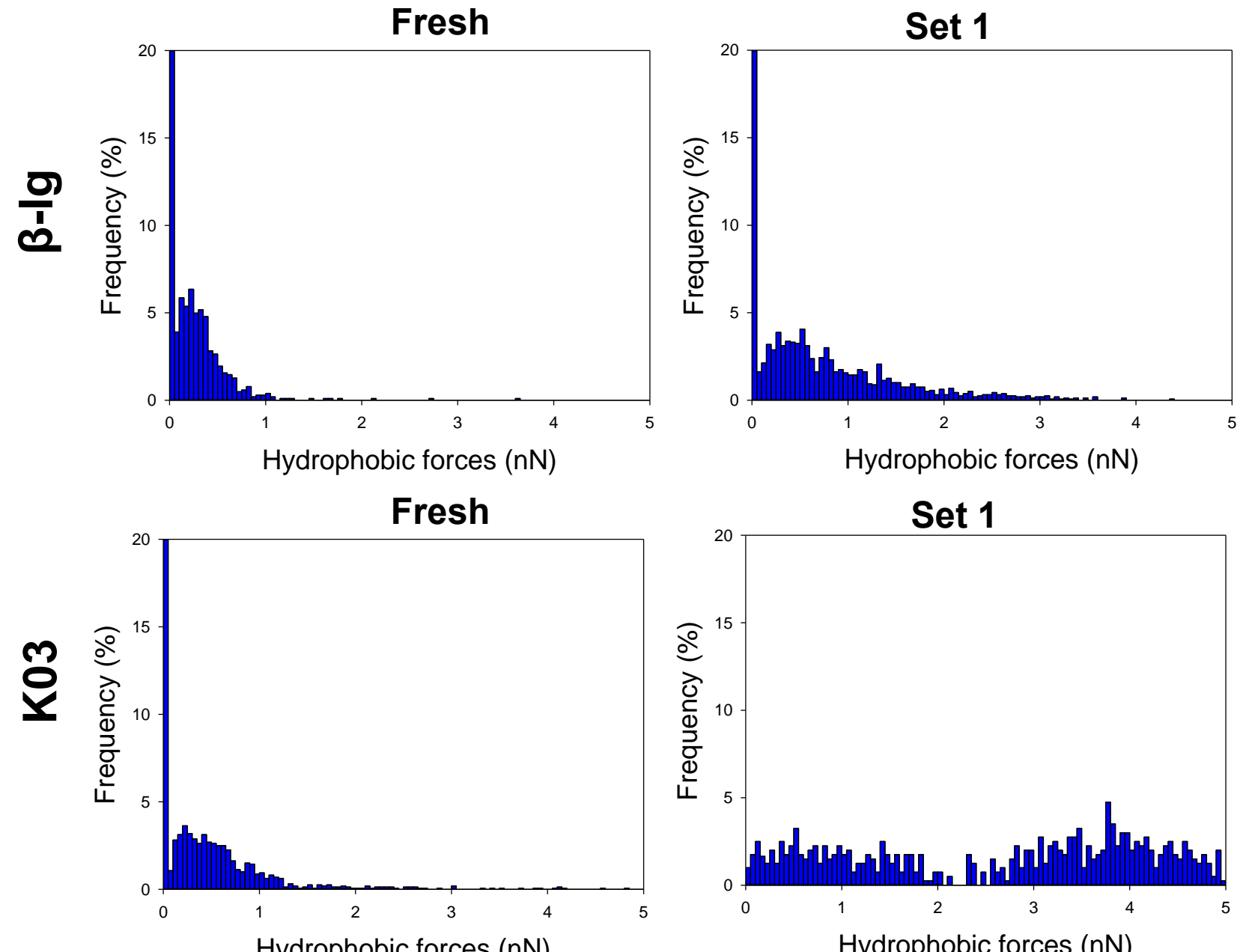

Hydrophobic forces $(\mathrm{nN})$

Figure S4. Example of statistic distribution of hydrophobicity for native/fresh and stored K03 and $\beta$-lg powder (histograms) and their corresponding spatial distribution as insets. 


\begin{tabular}{|c|c|c|c|c|c|}
\hline & \multicolumn{5}{|c|}{ Surface hydrophobicity of $\beta$-lg } \\
\hline & Comparison & Diff of Ranks & $\mathbf{Q}$ & $\mathbf{P}$ & $P<0.050$ \\
\hline$\stackrel{Ð}{\leftrightarrows}$ & Fresh vs Set 1 & 7966.872 & 36.693 & $<0.001$ & Yes \\
\hline & Fresh vs Set 2 & 10059.022 & 56.024 & $<0.001$ & Yes \\
\hline 焉造 & Fresh vs Set 3 & 3279.085 & 15.738 & $<0.001$ & Yes \\
\hline 芑 & Fresh vs Set 4 & 6266.969 & 31.346 & $<0.001$ & Yes \\
\hline 考需 & Fresh vs Set 5 & 1808.411 & 9.444 & $<0.001$ & Yes \\
\hline 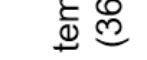 & Fresh vs Set 6 & 5071.896 & 28.545 & $<0.001$ & Yes \\
\hline
\end{tabular}

84

Table S1. Statistical analysis of surface hydrophobicity data using Dunn's method according to

86

87

88

89

90

91

92

93

94

95

96

97

98

99

100

101

102

103

104

105

106

107

108

Kruskal-Wallis One Way Analysis of Variance on Ranks (ANOVA). H = 7393.114 with 6 degrees of freedom. $(\mathrm{P}=<0.001)$ for $\beta-\lg$ particles groups and $\mathrm{H}=2748.396$ with 6 degrees of freedom. ( $\mathrm{P}=<0.001)$ for K03 particles groups. The differences in the median values among the treatment groups are greater than would be expected by chance; there is a statistically significant difference $(\mathrm{P}=0.001)$.

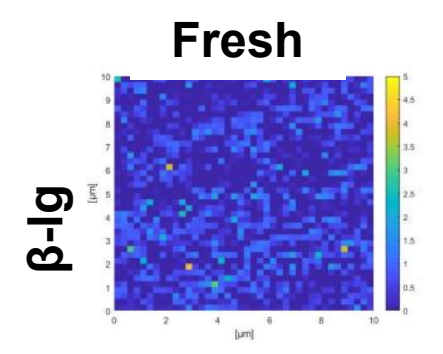

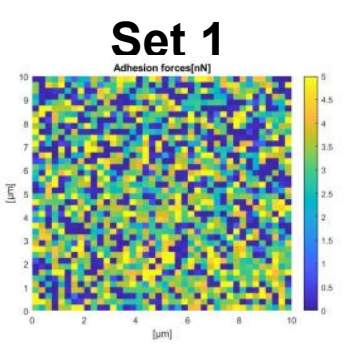

Set 2
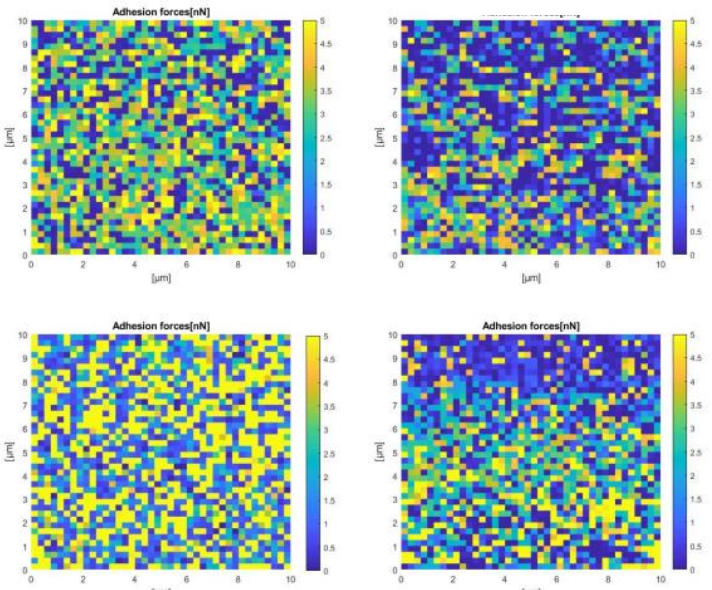

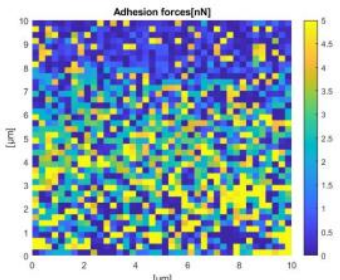

Set 3
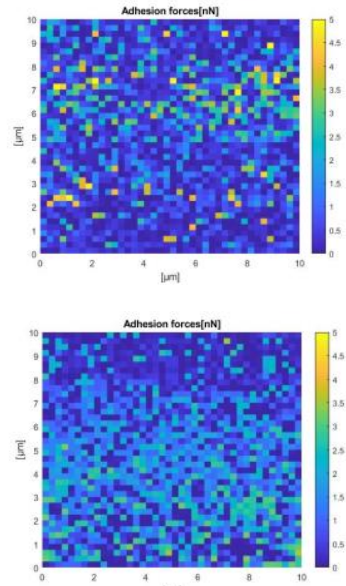

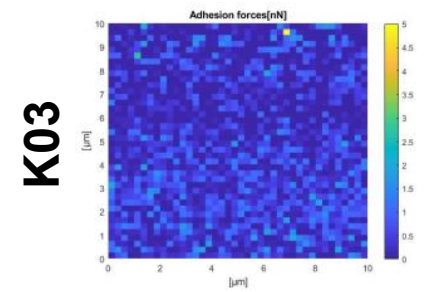

Figure S5. Representative spatial distribution of the surface hydrophobicity of b-lg K03 milk powder under high temperature storage. The color-scale bar reveals low adhesion force when the region is blue and high adhesion force when it is yellow. 
Fresh

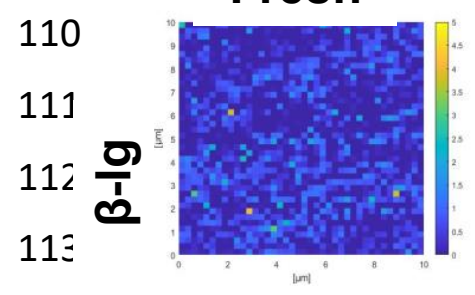

114

115

116

117

118

119

120

121

122

123

124

125

126

127

128

129

130

131

132

133

134

135

4

25
Set 4
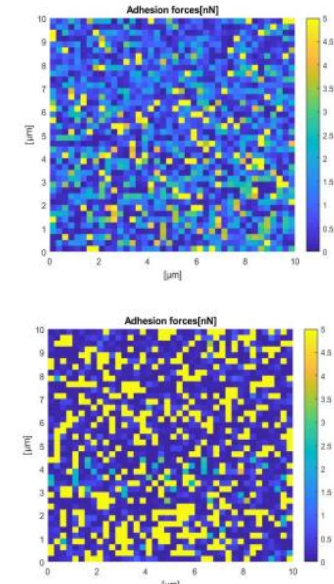

Set 5
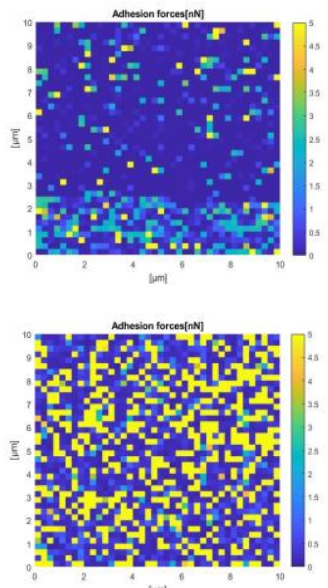

Set 6
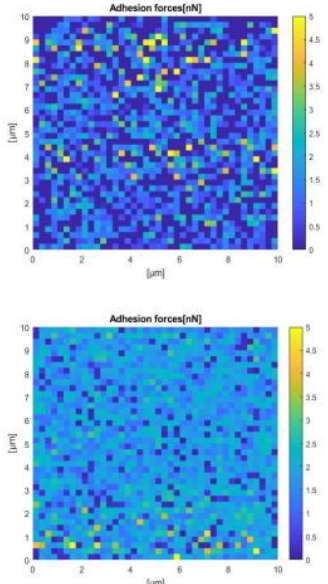

Figure S6. Representative spatial distribution of the surface hydrophobicity of b-lg K03 milk powder under low temperature storage. The color-scale bar reveals low adhesion force when the region is blue and high adhesion force when it is yellow.

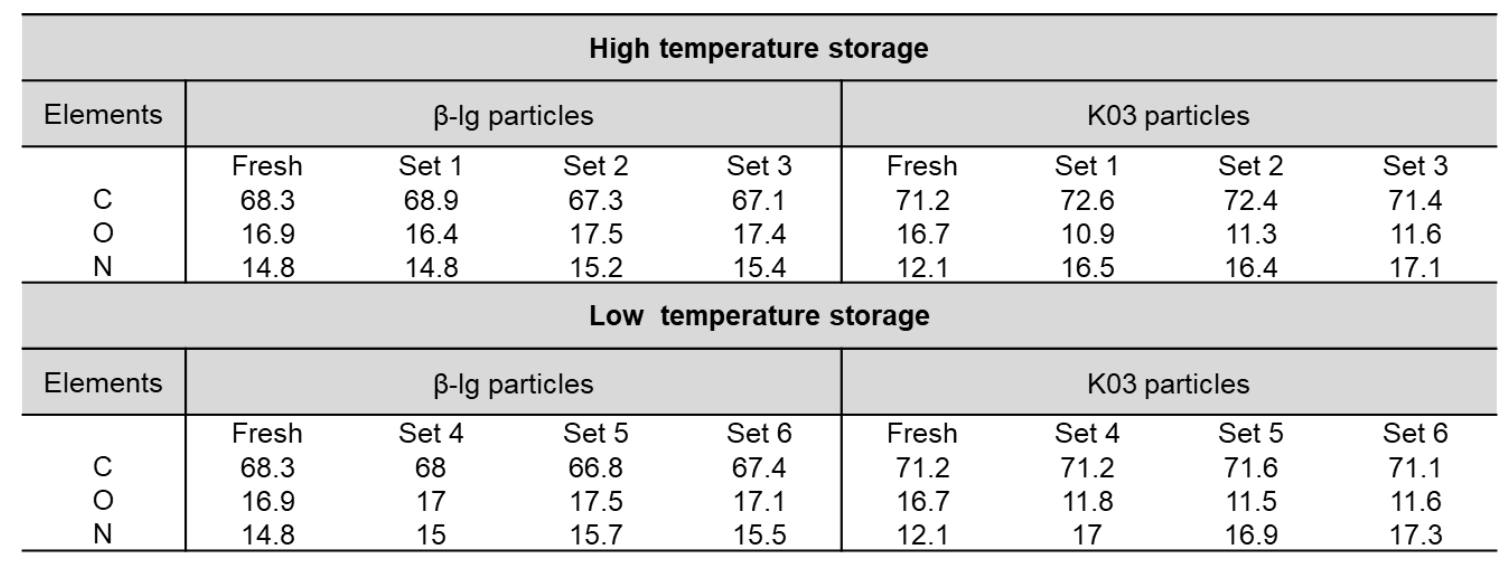

Table S2. XPS analysis of $\beta-\lg$ and K03 milk powder particles before and after high and low temperature storage (relative atomic percentage, $\%$ ). 

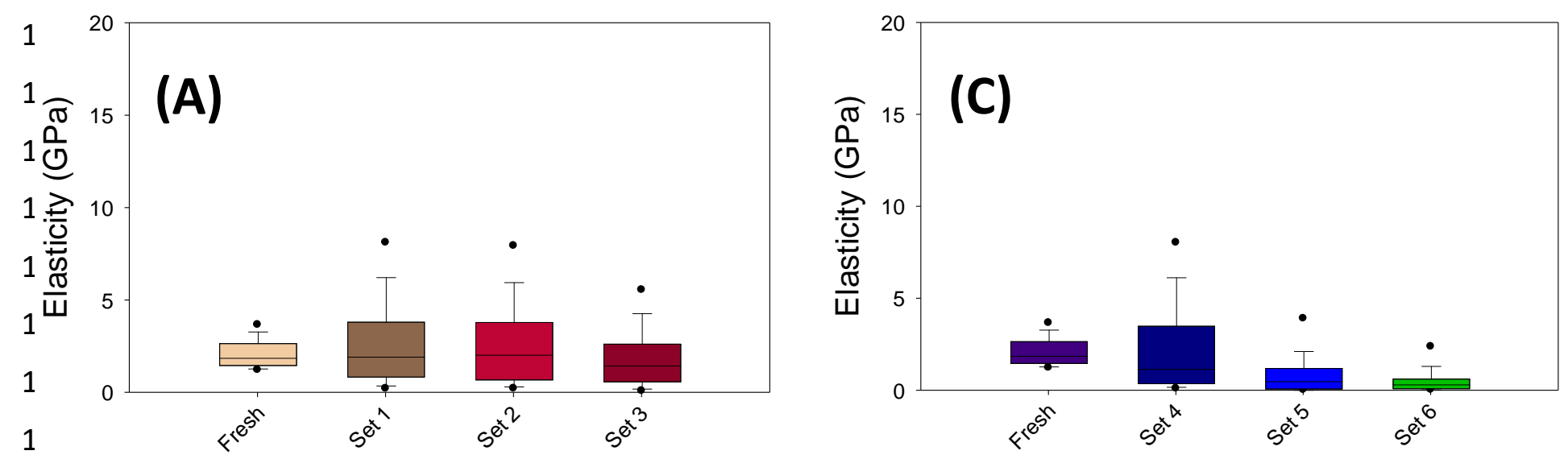

1

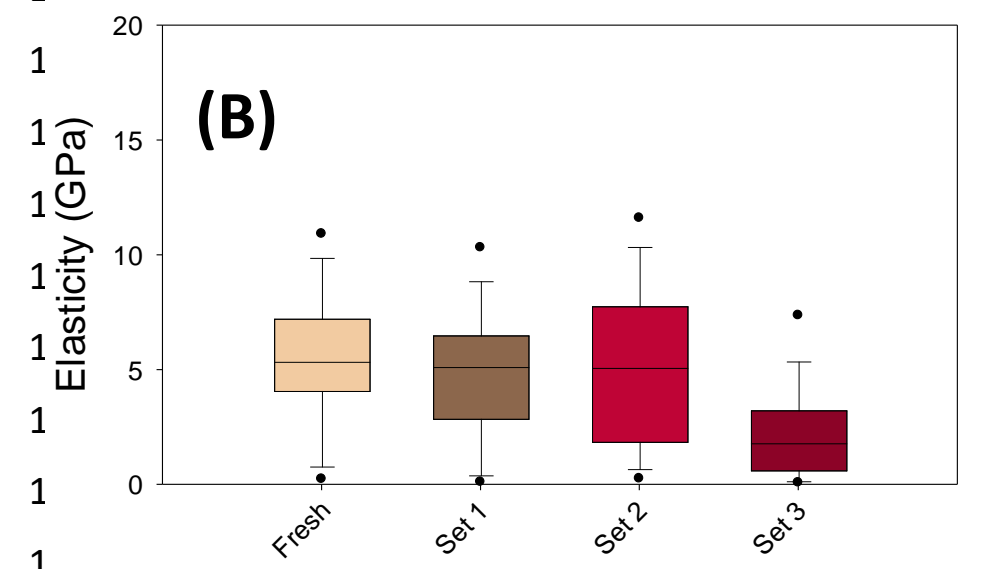

1 .

High temperature storage

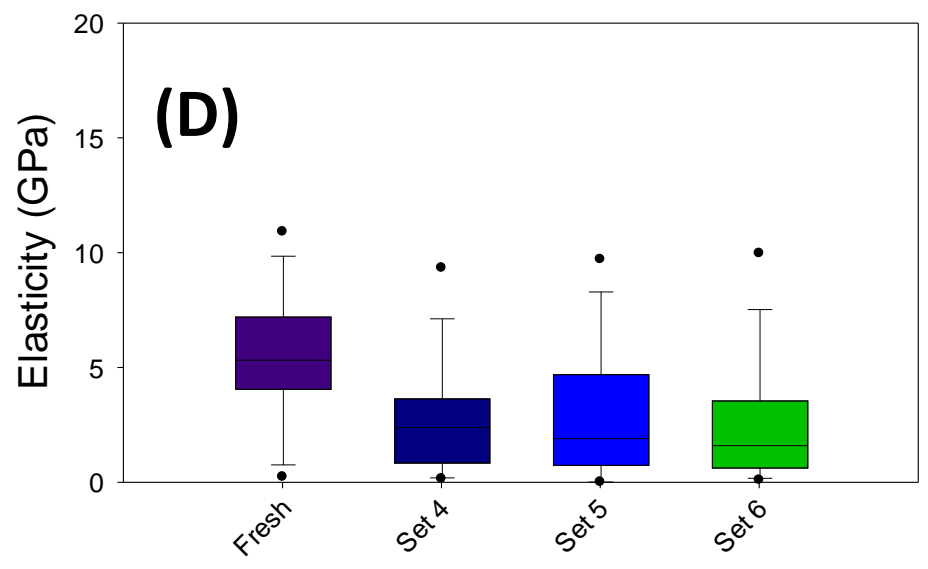

Low temperature storage

155 Figure S7. Evolution of the particles elasticity under high temperature storage for $\beta-\lg (\mathrm{A})$ and

$156 \mathrm{~K} 03$ (B) particles and under low temperature storage for $\beta-\lg$ (C) and K03 (D) particles.

157 Kruskal-Wallis One Way Analysis of Variance on Ranks (ANOVA) analysis performed on the

158 whole data sets indicated that there is a statistically significant differences $(\mathrm{P}=<0.001)$ between

159 all set conditions.

160

161

162

163

164

165

166

167

168

169 
Fresh

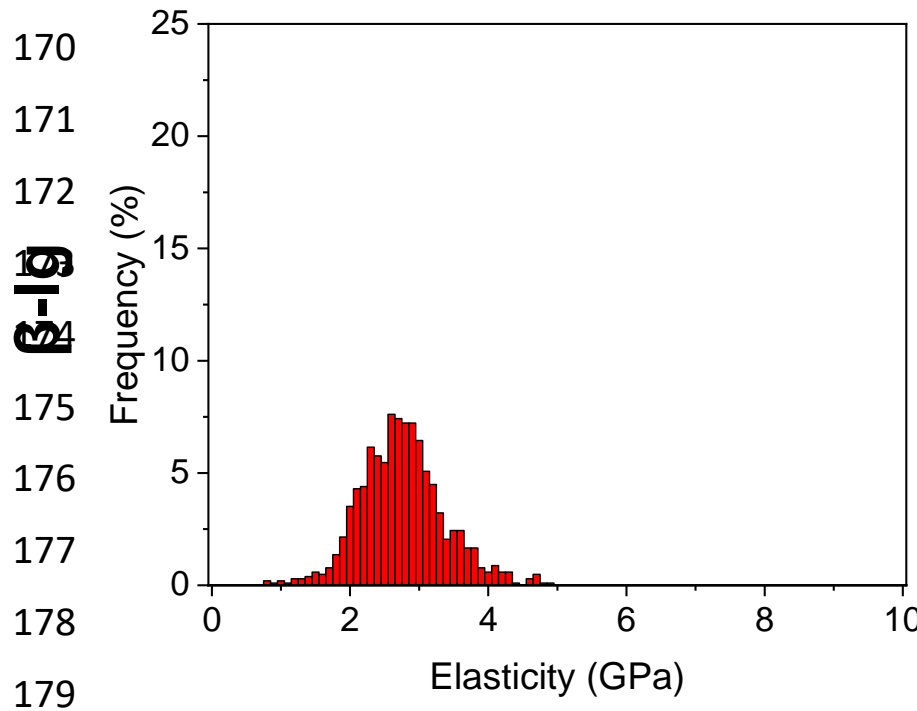

179

180

181

182

183
184
me
$\frac{186}{18}$ 187

188

189

190

191

192

193

194

195

196

197

198

199

200

201

202

203
Set 1

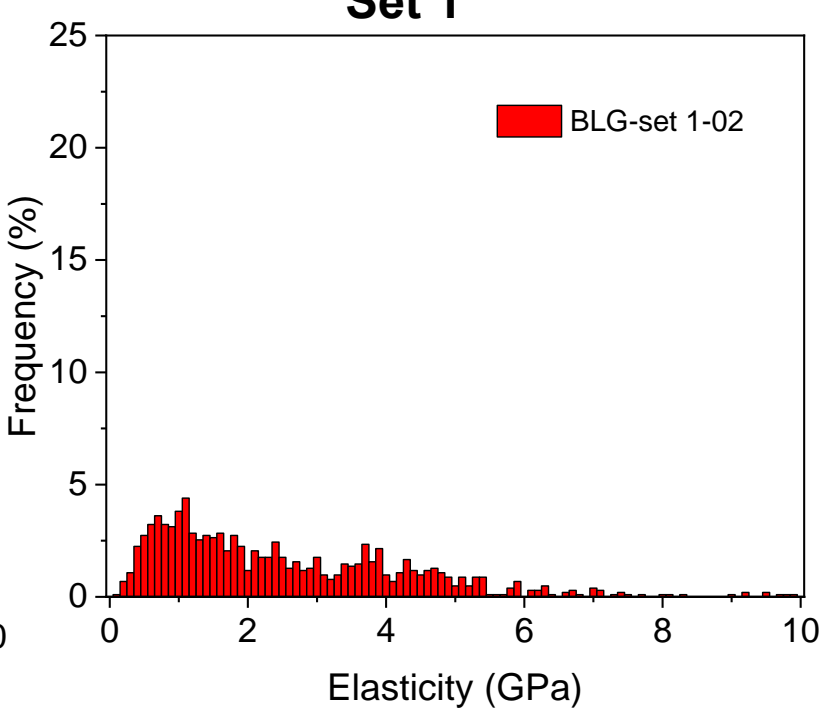

Set 1

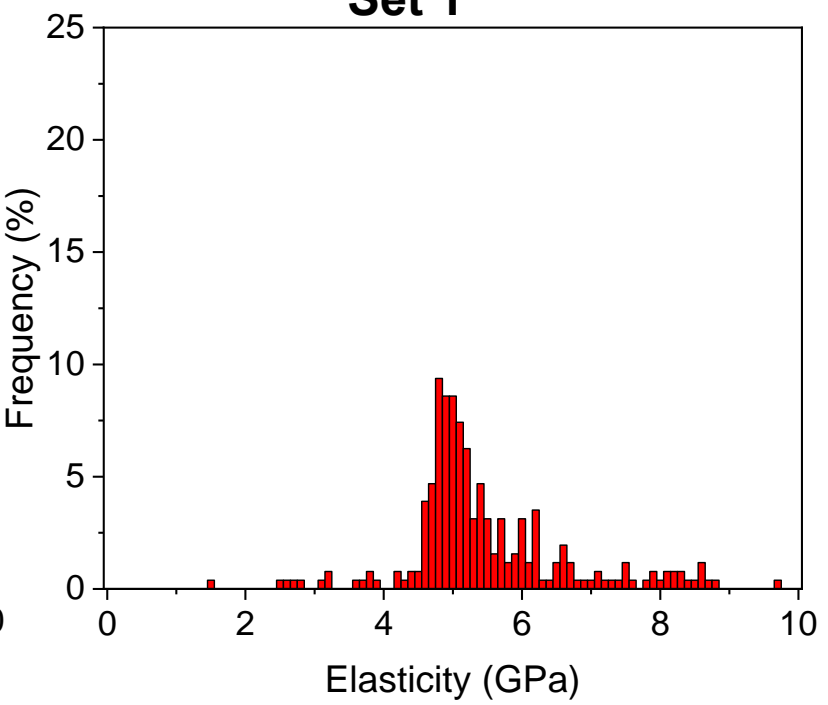




\begin{tabular}{|c|c|c|c|c|c|}
\hline & \multicolumn{5}{|c|}{ Nanomechanical properties of $\beta$-Ig particles } \\
\hline & Comparison & Diff of Ranks & $\mathbf{Q}$ & $\mathbf{P}$ & $P<0.050$ \\
\hline \multirow{3}{*}{ 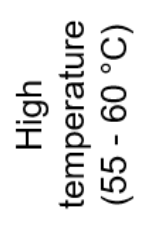 } & Fresh vs Set 1 & 861.511 & 5.15 & $<0.001$ & Yes \\
\hline & Fresh vs Set 2 & 1090.297 & 6.955 & $<0.001$ & Yes \\
\hline & Fresh vs Set 3 & 3219.574 & 21.402 & $<0.001$ & Yes \\
\hline \multirow{5}{*}{ 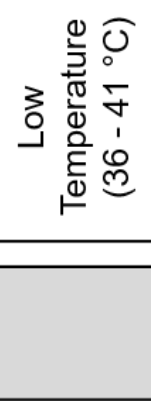 } & Fresh vs Set 4 & 3346.905 & 11.863 & $<0.001$ & Yes \\
\hline & Fresh vs Set 5 & 8968.913 & 52.314 & $<0.001$ & Yes \\
\hline & Fresh vs Set 6 & 10772.917 & 55.804 & $<0.001$ & Yes \\
\hline & \multicolumn{5}{|c|}{ Nanomechanical properties of $\mathrm{KO3}$ particles } \\
\hline & Comparison & Diff of Ranks & $\mathbf{Q}$ & $\mathbf{P}$ & $P<0.050$ \\
\hline \multirow{3}{*}{ 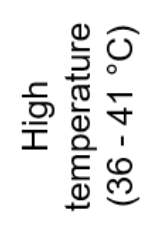 } & Fresh vs Set 1 & 1230.816 & 7.675 & $<0.001$ & Yes \\
\hline & Fresh vs Set 2 & 1053.433 & 6.108 & $<0.001$ & Yes \\
\hline & Fresh vs Set 3 & 7287.809 & 47.2 & $<0.001$ & Yes \\
\hline \multirow{3}{*}{ 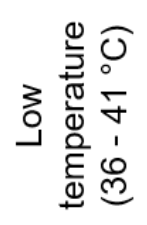 } & Fresh vs Set 4 & 5891.695 & 36.945 & $<0.001$ & Yes \\
\hline & Fresh vs Set 5 & 5960.915 & 40.43 & $<0.001$ & Yes \\
\hline & Fresh vs Set 6 & 6890.029 & 38.225 & $<0.001$ & Yes \\
\hline
\end{tabular}

223 Table S3. Statistical analysis of surface hydrophobicity data using Dunn's method according to

224 Kruskal-Wallis One Way Analysis of Variance on Ranks (ANOVA). H = 5897.089 with 6 225 degrees of freedom. ( $\mathrm{P}=<0.001)$ for $\beta-\lg$ particles groups and $\mathrm{H}=4219.658$ with 6 degrees of 226 freedom. ( $\mathrm{P}=<0.001)$ for $\mathrm{K} 03$ particles groups. The differences in the median values among 227 the treatment groups are greater than would be expected by chance; there is a statistically 228 significant difference $(\mathrm{P}=0.001)$. 


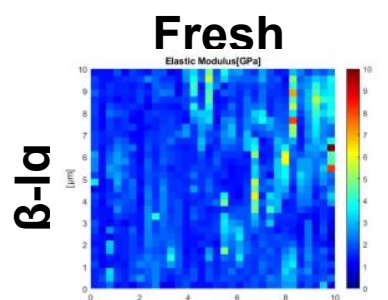

Set 1

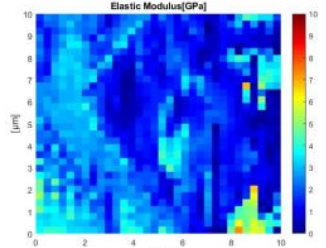

Set 2

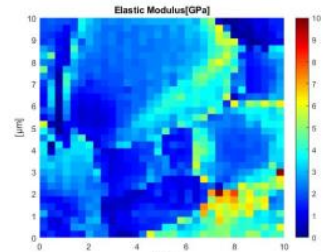

Set 3
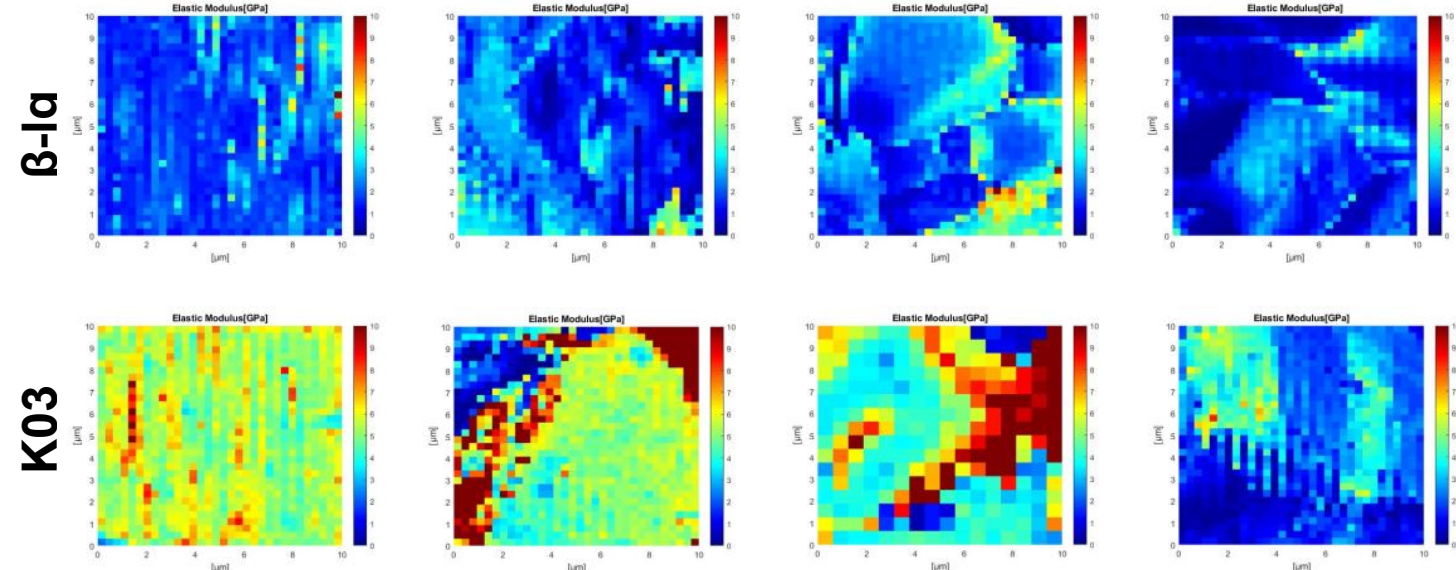

247

Figure S9. Representative spatial distribution of elasticity of b-lg K03 milk powder particles under high temperature storage. The color-scale bar reveals low adhesion force when the region is blue and high adhesion force when it is yellow.
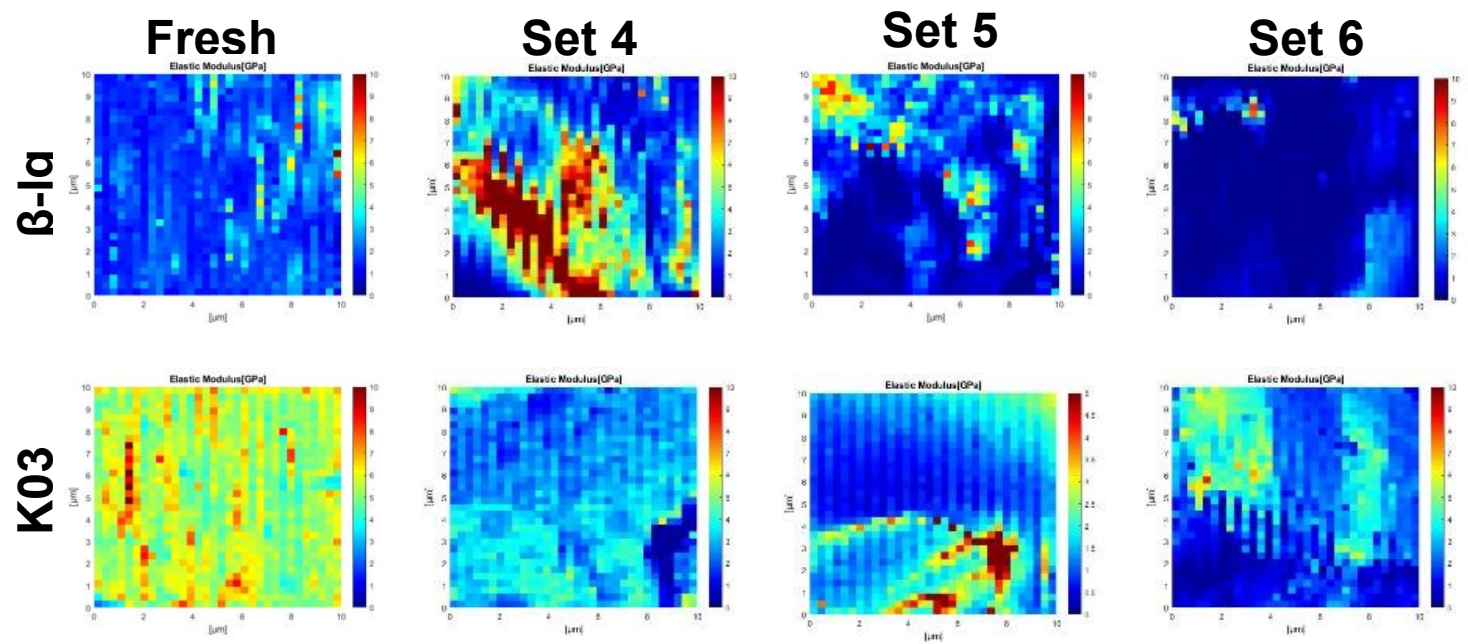

Figure S10. Representative spatial distribution of elasticity of b-lg K03 milk powder particles under low temperature storage. The color-scale bar reveals low adhesion force when the region is blue and high adhesion force when it is yellow. 